Florida International University

FIU Digital Commons

$11-13-2019$

\title{
Molecular Mechanism of DREAM Dimerization and Interactions with a Non-physiological Ligand Zn2+.
}

Maria D. Santiago Estevez

msant203@fiu.edu

Follow this and additional works at: https://digitalcommons.fiu.edu/etd

Part of the Chemistry Commons

\section{Recommended Citation}

Santiago Estevez, Maria D., "Molecular Mechanism of DREAM Dimerization and Interactions with a Nonphysiological Ligand Zn2+." (2019). FIU Electronic Theses and Dissertations. 4320.

https://digitalcommons.fiu.edu/etd/4320

This work is brought to you for free and open access by the University Graduate School at FIU Digital Commons. It has been accepted for inclusion in FIU Electronic Theses and Dissertations by an authorized administrator of FIU Digital Commons. For more information, please contact dcc@fiu.edu. 


\section{FLORIDA INTERNATIONAL UNIVERSITY}

Miami, Florida

\section{MOLECULAR MECHANISM OF DREAM DIMERIZATION AND INTERACTIONS WITH A NON-PHYSIOLOGICAL LIGAND $\mathrm{Zn}^{2+}$}

A thesis submitted in partial fulfillment of the

requirements for the degree of

MASTER OF SCIENCE

in

CHEMISTRY

by

Maria D. Santiago

2019 
To: Dean Michael R. Heithaus

College of Arts, Sciences and Education

This dissertation, written by Maria D. Santiago, and entitled Molecular Mechanism of DREAM Dimerization and Interactions with a Non-physiological Ligand $\mathrm{Zn} \mathrm{n}^{+}$, having been approved in respect to style and intellectual content, is referred to you for judgment.

We have read this dissertation and recommend that it be approved.

Xiaotang Wang

Francisco Fernandez Lima

Jaroslava Miksovska, Major Professor

Date of Defense: November 13, 2019

The dissertation of Maria D. Santiago is approved.

Dean Michael R. Heithaus

College of Arts, Sciences and Education

Andrés G. Gil

Vice President for Research and Economic Development and Dean of the University Graduate School

Florida International University, 2019 
C Copyright 2019 by Maria D. Santiago

All rights reserved. 


\section{DEDICATION}

To my mother Felicia Estevez and sisters Maria Jose Santiago and Maria Daniel Santiago who push me to be a better person every day. 


\section{ACKNOWLEDGMENTS}

I want to thank the Lord Jesus Christ for putting all these beautiful amazing people in my life, each one of them is a blessing and have made me a better person.

Firstly, I would like to acknowledge my advisor and mentor Dr. Jaroslava Miksovska, her support and guidance have been crucial at every moment; none of this thesis or any graduate degree would have been possible without her. She took a chance on me and has been fighting every obstacle by my side since the beginning. I will always be eternally grateful for her commitment as a mentor and as an exceptional human being.

I would also like to acknowledge my committee members Dr. Xiaotang Wang and Dr. Francisco Fernadez-Lima, their kindness and feedback has been greatly appreciated through these two years.

I want to thank my lab partners and friends for their help and support in the lab. Dr. Antonija Tangar, Ruipeng Lei, Samiol Azam, Tetyana Shvets, Adriana Riveron, Sasha Rodriguez, Setareh Sakhdari, Israel Castillo, Joana Almeida, Claribel Utria, Maria Isabel Frias, and Magali Autie. I want to thank my friends Haydee Linares Rosales, Tumpa Dasgupta Carolina Pastorelli and Yoniel Olivares for their emotional support and for giving friendship its true meaning.

I am indebted to my mother Felicia Estevez who has shown me to never give up on anything and has been the reason I always keep moving forward. My sisters Maria Jose Santiago and Maria Daniel Santiago who has been the greatest support and infinite help 
since I can remember, they are my biggest blessing; everything is possible with them by my side.

Lastly, I am thankful to the BD Fellowship who provided the financial support during these two years, Dr. Sonja Montas -Hunter and Dr. Alla Mirzoyan who have shown me kindness and support since the beginning. 


\section{ABSTRACT OF THE THESIS \\ MOLECULAR MECHANISM OF DREAM DIMERIZATION AND \\ INTERACTIONS WITH A NON-PHYSIOLOGICAL LIGAND Zn^2+ \\ by \\ Maria D. Santiago}

Florida International University, 2019

Miami, Florida

Professor Jaroslava Miksovska, Major Professor

Downstream Regulatory Element Antagonist Modulator (DREAM) belongs to the family of neuronal calcium sensor proteins and it is involved in several processes in the brain.

Zinc has been shown to bind to recoverin, with submillimolar affinity. Based on the high sequence homology between the NCS family, it is proposed that DREAM can also serve as an intracellular target for $\mathrm{Zn} 2+$. Fluorescence and $\mathrm{CD}$ studies confirm that zinc binds to DREAM with a of $\mathrm{K} d=4 \mu \mathrm{M}$, triggering changes in the proteins' tertiary structure.

The calcium association to DREAM leads to the formation of a $\mathrm{Ca} 2+$ bound dimer, while in the apo state, a monomer-tetramer equilibrium was observed. A chimeric version of DREAM was prepared by mutating the residues involved in dimerization. DREAM-NCS1 properties were investigated using spectroscopic techniques. These results point towards the role of hydrophobic interactions and salt bridges in stabilizing the dimer and propagating allosteric signals. 


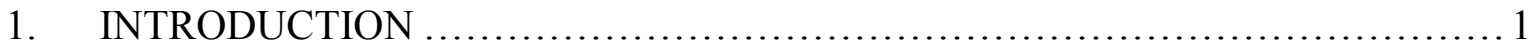

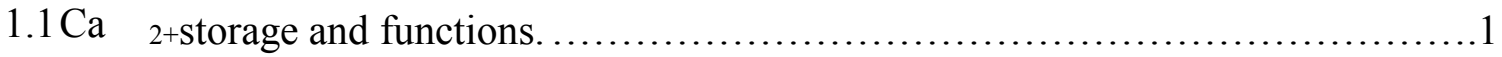

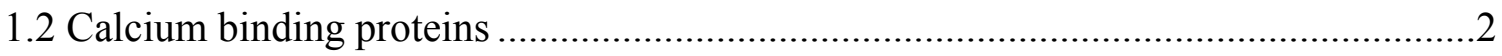

1.2 Calmodulin as a model protein for EF-hands calcium sensors ......................................

1.3 Calcium coordination and binding site in $\mathrm{EF}$-hand proteins ......................................

$1.4 \mathrm{Ca} \quad 2+$ and neuronal calcium sensors in the brain ..................................................

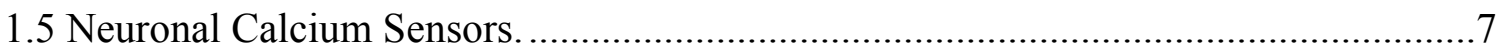

1.6 Downstream Regulatory Element Antagonist Modulator...........................................10

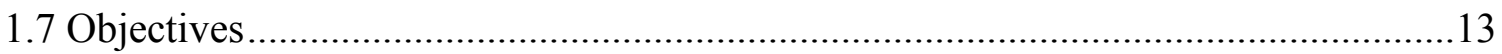

2. MATERIALS AND METHODS ................................................. 16

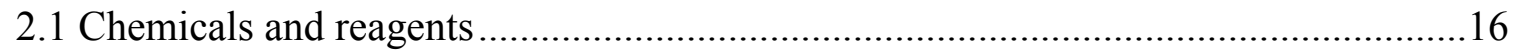

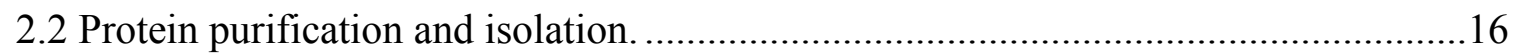

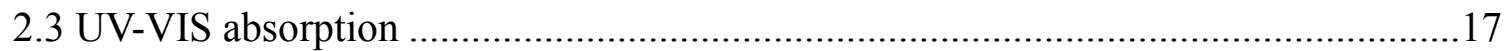

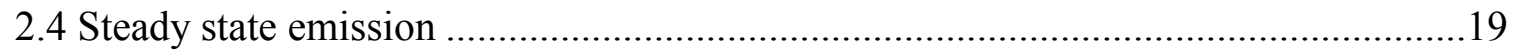

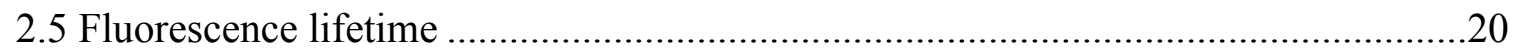

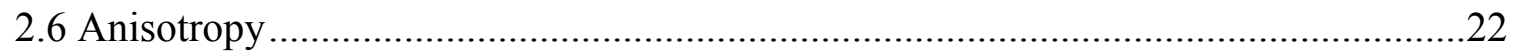

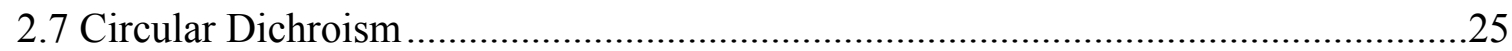

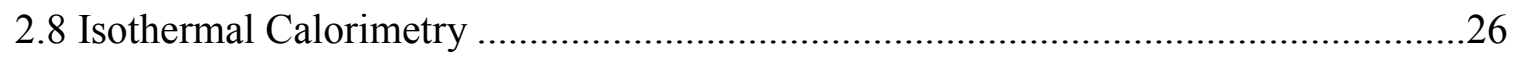

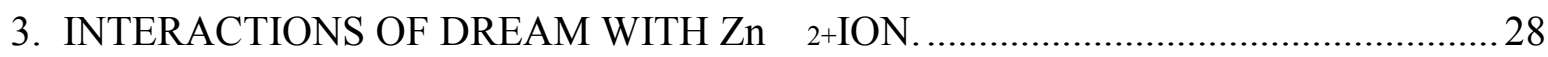

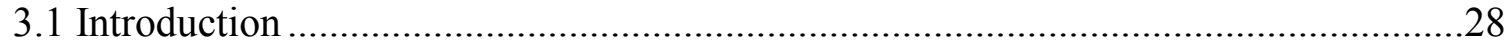

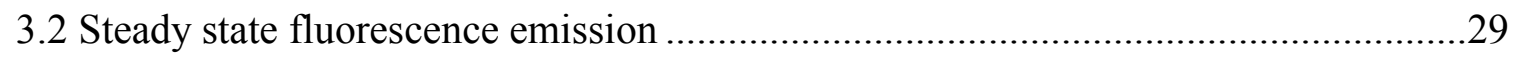

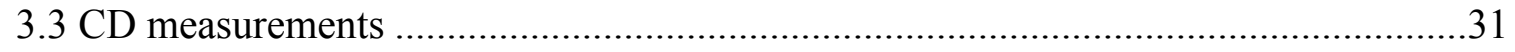

3.4 Impact of Zn 2+on DREAM interactions with hydrophobic probe, 1,8-ANS ..........32

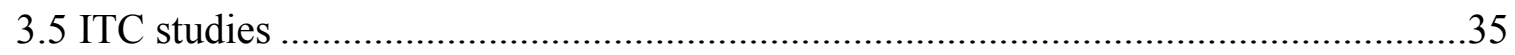

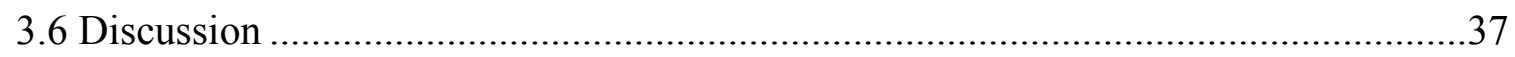


4. MOLECULAR MECHANISM OF DREAM DIMERIZATION

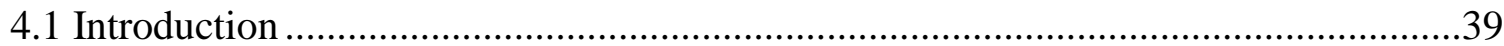

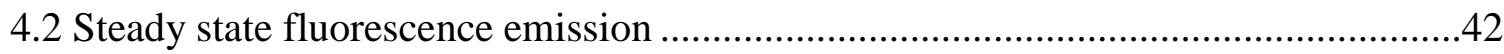

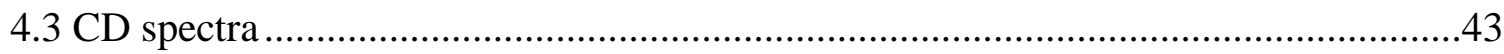

$4.4 \mathrm{Ca}^{2+}$ triggered exposure of hydrophobic cavities ..................................................44

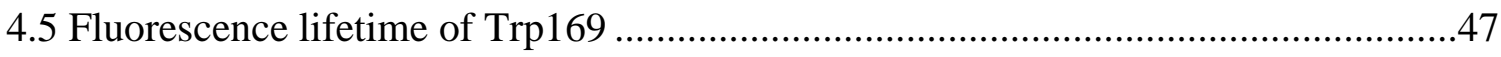

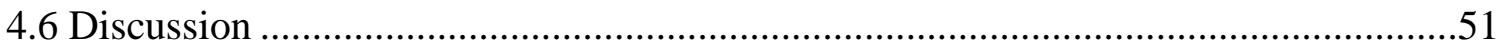

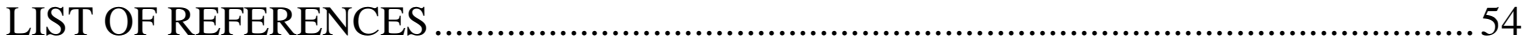


Table 1.1: Sequence of amino acid residues in canonical calcium binding loop. Adapted from (Gifford et al., 2007).

Table 2.1: Extinction coefficient values used in this study

Table 3.1: Dissociation constant for $\mathrm{Zn}$ 2+association to DREAMWT in the presence and absence of $\mathrm{Ca} 2+$

Table 3.2: Dissociation constant for 1,8 ANS - DREAMWT association with

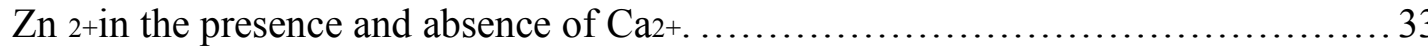

Table 3.3: 1,8 ANS lifetime for apo and Ca-DREAM WT in the presence of $\mathrm{Zn} 2+$ fitted to three exponential decays with a fixed lifetime for 1,8 ANS of $0.27 \mathrm{~ns}$. The lifetime values for 1,8 ANS bound to DREAM in the absence of $\mathrm{Zn}_{2}+$ were previously determined by Gonzalez (Gonzalez \& Miksovska, 2014)

Table 3.4: Equilibrium Dissociation constant of $\mathrm{Zn} \quad 2+$ binding to DREAM in the absence of $\mathrm{Ca} 2+$ Using one model sequential binding fitting.

Table 4.1: Dissociation constants and Hill coefficients for 1,8 ANS binding to DREAM-NCS1 and DREAM WT.

Table 4.2: : Emission decay parameters for DREAM WT and DREAM-NCS 1

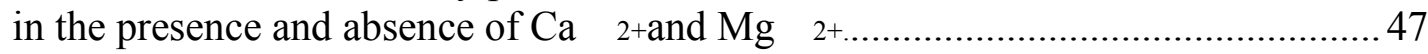

Table 4.3: Decay parameters for 1,8 ANS -DREAM WT and 1,8 ANSDREAM-NCS 1 complex in the presence and absence of $\mathrm{Ca}_{2}+$. The data were analyzed using a three exponential decay model. The data for DREAM WT are from Ref. Gonzalez and Miksovska, 2014...... 
Table 4.4: Dissociation constant for DREAM-NCS 1 interactions with Site 1

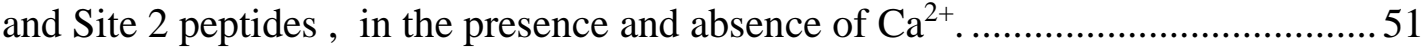




\section{LIST OF FIGURES}

FIGURE

PAGE

Fig. 1.1: Processes that control $\mathrm{Ca}^{2+}$ storage and release in the eukaryotic cell (Dong, Saikumar, Weinberg, \& Venkatachalam, 2006).

Fig. 1.2: Structure of Apo Calmodulin (PDB entry 1CFD) . B Structure of $\mathrm{Ca}^{2+}$ Calmodulin (PDB entry 1CLL)

Fig. 1.3: $\mathrm{Ca}^{2+}$ coordination by the canonical EF-hand illustrating the pentagonal bipyramidal coordination of the $\mathrm{Ca} 2+$ ion (continuous thin lines) and the hydrogen bonding pattern in the loop (dashed lines). The backbone $\mathrm{NH}$ groups are shown in black, the side-chain oxygen atoms in red, the $\mathrm{Ca} 2+$ ion in yellow and the coordinating water molecule in blue (Gifford et al., 2007).

Fig. 1.4: Calcium coordination in EF-hand 3 (A) and EF-hand 4 (B) of neuronal calcium sensor DREAM, (PDB entry 2JUL).

Fig. 1.5: Neuronal Calcium Sensor subfamilies classifications and main function Adapted from (Permiakov \& Kretsinger, 2011).

Fig. 1.6: DREAM structure determined by NMR. $\alpha$-helices are shown as ribbons with the $\mathrm{C}$-terminal domain shown in blue and the $\mathrm{C}$-terminal domain in red, $\mathrm{Ca}^{2+}$ ions are represented as green spheres. (PDB entry 2JUL) .....11

Fig. 1.7: Amino acid sequence of DREAM. The sequence corresponding to the individual EF-hands is shown in green, red, blue and yellow.

Fig. 2.1: Representation of the Perrin-Jablonski diagram. The arrows indicate the transition between the different electronic states. Radiative processes are shown, absorption is represented by the blue arrow, emission is represented by the bright green arrow and phosphorescence is represented by the orange arrow. The non-radiative processes, such as internal conversion, intersystem crossing and vibrational relaxation are shown in red, flat green and maroon respectively.

Fig. 2.2: Position of the polarizers for the steady-state anisotropy measurements. The Direction of the propagation of the excitation light and collected 
emitted light are sow as thin black arrows, the orientation of the polarizer placed in the excitation and emission path are shown in green. (Adapted from Jameson 2004).

Fig. 2.3: Structure of FITC

Fig. 2.4: Typical CD spectra, showing the three major secondary structures of proteins, $\alpha$-helix, $\beta$-sheet and random coil with distinctive peak at specific wavelengths. Adapted from Wei et al. (Wei, Thyparambil, \& Latour, 2014).

Fig. 2.5: ITC instrumentation. Adapted from (Martinez et al., 2013)

Fig. 3.1: Sequence similarity among recoverin( PDB entry 1JSA) and DREAM (PDB entry 2JUL), identical residues in green, similar residues in pink ,sequence mismatch in blue and insertion/deletion in brown. Obtained from RCSB PDB Protein Comparison Tool. Smith-Waterman sequence alignment (Smith \& Waterman, 1981)

Fig. 3.2: Steady-state fluorescence emission of Trp for DREAM-WT upon $500 \mu \mathrm{M}$ $\mathrm{Zn}^{2+}$ addition in the presence and absence of $\mathrm{Ca}^{2+}$ and/or $\mathrm{Mg}^{2+}$ 30

Fig. 3.3: Trp fluorescence emission for the $\mathrm{Zn}^{2+}$ association to $\mathrm{Ca}^{2+}$ (right) and apo (left) DREAM WT

Fig. 3.4: Secondary structure characterization of DREAM WT upon $\mathrm{Zn}^{2+}$ addition in the absence and presence of $\mathrm{Ca}^{2+}, \mathrm{Mg}^{2+}$ and $\mathrm{Ca}^{2+} \mathrm{Mg}^{2+}$.

Fig. 3.5: Emission spectra of 1,8 ANS-DREAM WT complex in the presence and/or absence of $\mathrm{Ca}^{2+}, \mathrm{Mg}^{2+}$ and $\mathrm{Zn}^{2+}$.....

Fig. 3.6: $\mathrm{Zn}^{2+}$ association to $\mathrm{Ca}^{2+}$ and Apo DREAM WT in the presence of 1,8 ANS.

Fig. 3.8: ITC Isotherms for $\mathrm{Zn}^{2+}$ association to DREAM in the absence of $\mathrm{Ca}^{2+}$, the upper panel refers to thermal power as function of time, and the lower panel represent the integrated reaction heat $\Delta \mathrm{H}$ in $\mathrm{kcal} / \mathrm{mol}$. 
Fig. 4.1: The structure of the dimeric form of recovering (left) and VILIP-1 (right) in $\mathrm{Ca}^{2+}$ bound form. Individual monomers are colored in yellow and blue and side chains of residues in the binding interfaces are shown in red. Adapted from Ames 2018 (Ames, 2018).

Fig. 4.2: Sequence of mouse DREAM WT (red) with a start methionine residue (green) and a C-terminus His-tag (blue) connected by tripeptide linker (green). The DREAM-NCS (black) has identical sequence to the DREAM WT except residues L158, Leu159 replaced by Thr and Ser and the loop between EF-hand 3 and 4 (shown in yellow) replaced by the amino acid sequence found in human NCS-1 (shown in bold red).....41

Fig. 4.3 : Model structure of DREAM dimer based on the NMR structure of DREAM monomer (PDB entry 2JUL). Left panel shows hydrophobic interactions between Leu 155, 159 and 251 and right panel show a salt bridge between Arg 200, Arg 207 (in blue) and Glu 103 (in red).

Fig. 4.4: Steady-state fluorescence emission of Trp for DREAM-WT (left) and DREAM-NCS1 (right) in the presence and absence of $\mathrm{Ca}^{2+}$ and/or $\mathrm{Mg}^{2+}$.

Fig. 4.5: Circular dichroism spectra for DREAM WT (left), and DREAM-NCS1 (right) in the presence and absence of $\mathrm{Ca}^{2+}$ and/or $\mathrm{Mg}^{2+}$.

Fig. 4.6: 1,8 ANS-DREAM-NCS 1 emission spectra upon $\mathrm{Ca}^{2+}, \mathrm{Mg}^{2+}$ and $\mathrm{Ca}^{2+} \mathrm{Mg}^{2+}$ addition.

Fig. 4.7: Titration curves for 1,8-ANS binding to apoDREAM-NCS 1 (left) and $\mathrm{Ca}^{2+}$ DREAM-NCS 1 (right).

Fig. 4.8: Frequency domain Trp intensity decay for apo DREAM-NCS 1(left) and $\mathrm{Ca}^{2+}$ bound DREAM-NCs 1 (right). The solid lines correspond to the fit of the experimental data using a sum of three exponential decay model.

Fig. 4.9: Cartoon presentation of the interactions between FITC labeled site 1 (shown in purple) and DREAM (shown in light blue). $\mathrm{Ca}^{2+}$ ions are shown in yellow 
Fig. 4.10: Increase in anisotropy for Site 2 titration with DREAM -NCS 1 in the presence (left) and absence (right) of $\mathrm{Ca}^{2+}$. The solid line corresponds to the fit of the experimental data using quadratic equation (Eq. 2.5) .......50

Fig. 4.11: Increase in anisotropy for Site 1 titration with DREAM -NCS 1 in the presence (left) and absence (right) of $\mathrm{Ca}^{2+}$. The solid line corresponds to the fit of the experimental data using quadratic equation (Eq. 2.5) .......50 


\section{LIST OF ABREVIATIONS}

ABBREVIATION

$1,8-\mathrm{ANS}$

$\Delta \mathrm{H}$

$\Delta \mathrm{S}$

$\lambda \max$

$\mathrm{Ca} 2+$

$\mathrm{CaM}$

CD

DREAM

EDTA

EFX

EGTA

IPTG

KChIP

$\mathrm{Kd}$

$\mathrm{Mg}_{2+}$

TRIS
FULL NAME 1-anilinonaphthalene-8-sulfonic

acid

Enthalpy change

Entropy change

Emission maxima

Calcium

calmodulin

Circular dichroism

Downstream regulatory element antagonist modulator 2-

( $\{2-[$ Bis(carboxymethyl)amino] ethyl $\}$

(carboxymethyl)amino)acetic acid

EF-hand X

ethylene glycol-bis(2-aminoethylether)-N,N, $\mathrm{N}^{\prime}, \mathrm{N}^{\prime}$ tetraacetic

Isopropyl $\beta$-D-1-thiogalactopyranoside

Potassium channel interaction protein

Dissociation constant

Magnesium 2-Amino-2-hydroxymethyl-propane-1,3-diol 


\section{INTRODUCTION}

\section{$1.1 \mathrm{Ca}^{2+}$ storage and functions.}

Calcium is an intracellular messenger, which is involved in several processes such as neurotransmitter release, muscle contraction, and gene expression modulation. All these processes are regulated by the spatial and temporal location of $\mathrm{Ca}^{2+}$ (Lock, Smith, \& Parker, 2019) (Fig.ure 1.1). The intracellular $\mathrm{Ca}^{2+}$ concentration is around $10^{-8} \mathrm{M}$ and it is maintained by $\mathrm{Ca}^{2+}$-ATPase pumps and $\mathrm{Na}^{+} / \mathrm{Ca}^{2+}$ exchange, as well as sequestering in organelles such as the endosome, the Golgi apparatus, and the endoplasmic reticulum (Permyakov, E. A. \& Kretsinger, 2011). Intracellularly, the concentration of $\mathrm{Ca}^{2+}$ ions is regulated by ligand-gated $\mathrm{Ca}^{2+}$ channels. Calcium is released in the ER by inositol triphosphate (IP3) receptor linked channels and ryanodine receptors. In IP3 signaling, phospholipase c, activated through the GPCR pathway, cleaves phosphatidylinositol bisphosphate into IP3, which binds to IP3 receptors resulting in the release of $\mathrm{Ca}^{2+}$ from the ER. It is worth mentioning that IP3 signaling requires the co-stimulation of $\mathrm{Ca}^{2+}$ resulting in $\mathrm{Ca}^{2+}$ induced-Ca ${ }^{2+}$ release mechanism (Lock et al., 2019). Secondly, ryanodine receptors can also be activated by molecules such as caffeine and stimulate $\mathrm{Ca}^{2+}$ release (Permyakov, E. A. \& Kretsinger, 2011). In excitable cells such as neurons, the concentration of $\mathrm{Ca}^{2+}$ is mainly regulated by voltage gated $\mathrm{Ca}^{2+}$ channels. When the membrane potential of the neurons is between -60 to $-70 \mathrm{mV}$, the voltage gated $\mathrm{Ca}^{2+}$ channels are closed and the cell is in a resting state. On the other hand, when specific channels are activated $\mathrm{Ca}^{2+}$ enters the cell resulting in neuronal excitation (Ramirez, Gonzalez, Fissore, \& Carvacho, 2017). 


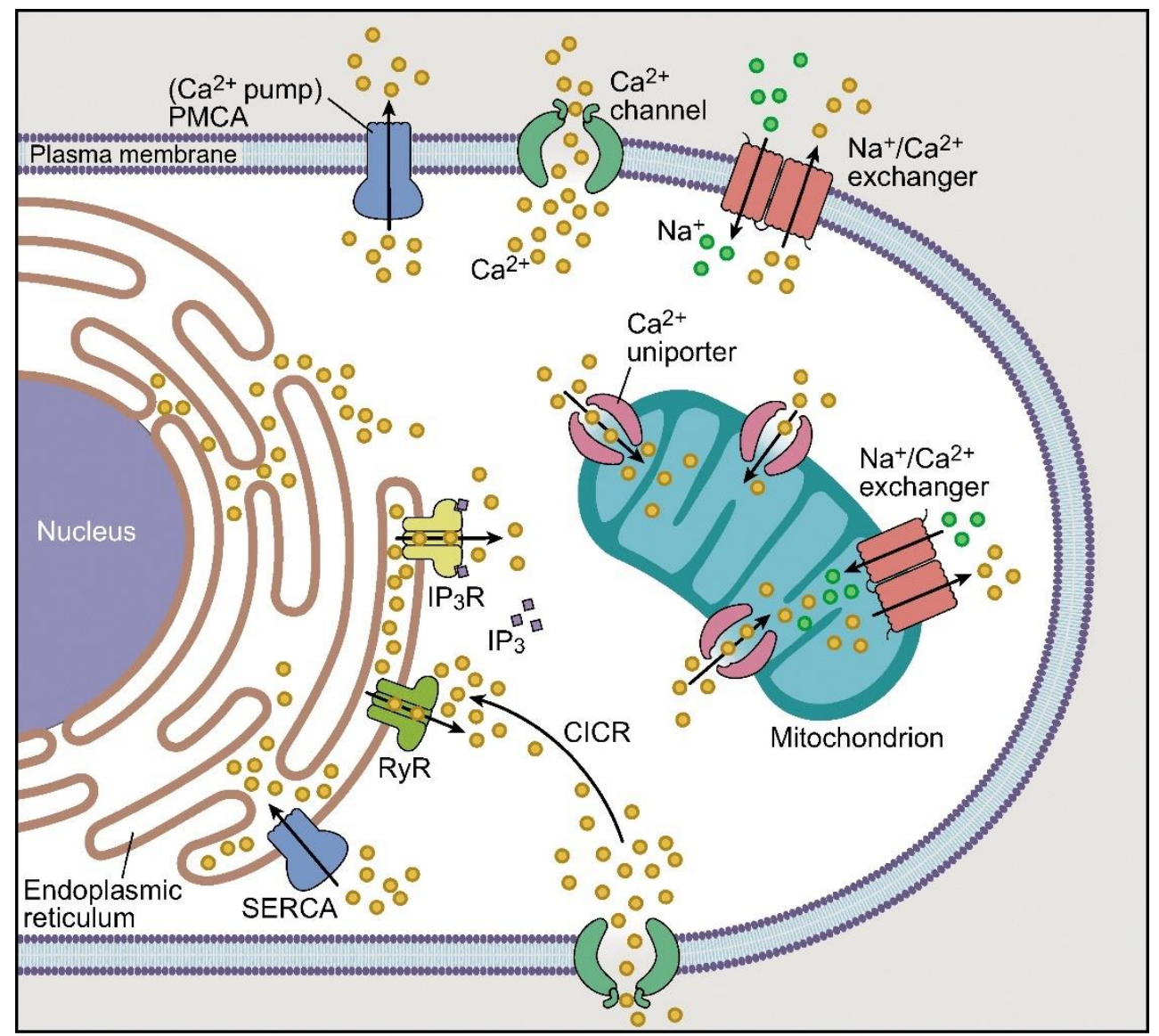

Fig. 1.1: Processes that control $\mathrm{Ca}^{2+}$ storage and release in the eukaryotic cell (Dong, Saikumar, Weinberg, \& Venkatachalam, 2006)

\subsection{Calcium binding proteins}

Calcium binding proteins (CBP) are traditionally divided into two groups, $\mathrm{Ca}^{2+}$ buffers and $\mathrm{Ca}^{2+}$ sensors (Permyakov \& Kretsinger, 2011). Calcium buffer proteins such as parvalbumin and calbildin are able to regulate intracellular $\mathrm{Ca}^{2+}$ concentration by binding to the metal and participating in signal transduction (Permyakov \& Kretsinger, 2011) . On the other hand, $\mathrm{Ca}^{2+}$ sensors undergo conformational changes upon $\mathrm{Ca}^{2+}$ binding, which ultimately modulate their affinity for intracellular partners. (Permyakov \& Kretsinger, 2011) 
1.2 Calmodulin as a model protein for EF-hands calcium sensors

The study of calmodulin has provided a model for the members of the EF-hands calcium sensors. Calmodulin is present in all eukaryotic cells (Permyakov \& Kretsinger, 2011) and it has been conserved during evolution because of its interactions with several partners in $\mathrm{Ca}^{2+}$ signal transduction pathways (Permyakov \& Kretsinger, 2011). The protein possesses 4 EF-hands and it is involved in several signal transduction pathways (Chazin, 2011; Permyakov \& Kretsinger, 2011). Calmodulin transduces the calcium signal by binding to $\mathrm{Ca}^{2+}$, which triggers a conformational change resulting in a less compact structure than the one in the apo form with exposed hydrophobic patches on the protein surface as shown in Fig. 1.2, allowing $\mathrm{Ca}^{2+}$ bound calmodulin to bind to the final target of the signaling pathway (Permyakov, E. A. \& Kretsinger, 2011).
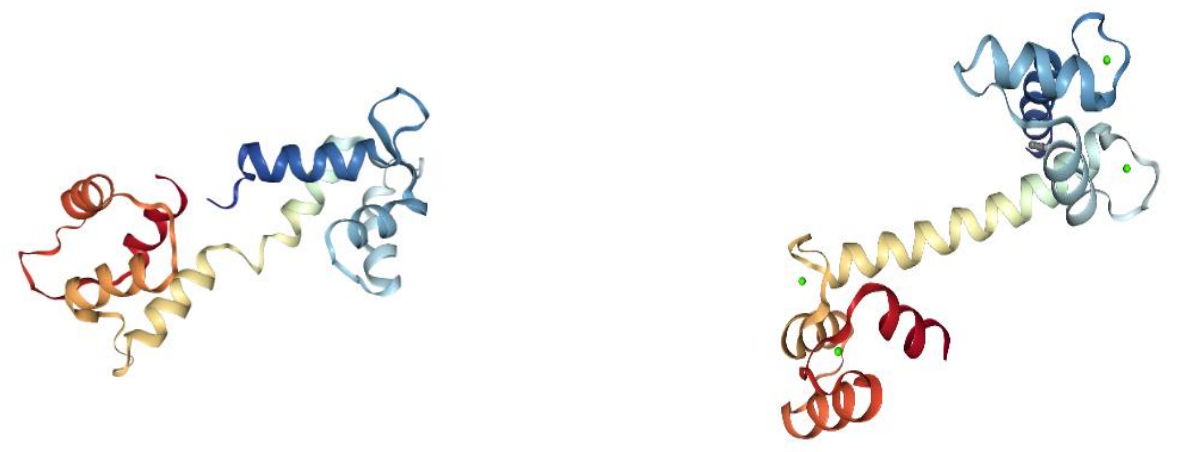

Fig. 1.2: Structure of Apo Calmodulin (PDB entry 1CFD) . Structure of $\mathrm{Ca}^{2+}-$ Calmodulin (PDB entry 1CLL) 
The most significant $\mathrm{Ca}^{2+}$ induced change in calmodulin is the change in the orientation of the helixes for each EF hand (Permyakov, E. A. \& Kretsinger, 2011). In the apo form, the first and last helixes are parallel to the central helix linker shown in Fig. 1.2, forming a compact hydrophobic core (Permyakov, E. A. \& Kretsinger, 2011). In the $\mathrm{Ca}^{2+}$ bound calmodulin, these helixes move away from the central helix linker, resulting in a change in the orientation with respect to the central helix linker, from $121-144^{\circ}$ in the apo form to 86-116 in the $\mathrm{Ca}^{2+}$ bound calmodulin (Permyakov \& Kretsinger, 2011). This observed reorientation upon $\mathrm{Ca}^{2+}$ binding produces a solvent exposure of methionine residues and concomitant formation of two hydrophobic concave patches that serve as binding sites for the intracellular partners (Permyakov \& Kretsinger, 2011).

1.3 Calcium coordination and- binding site in $\mathrm{EF}$-hand proteins

The calcium-binding site in EF-hand proteins is formed by a helix-loop-helix structure where $\mathrm{Ca}^{2+}$ is coordinated to the protein in a pentagonal bipyramidal geometry as shown in Fig. 1.3 (Gifford, Walsh, \& Vogel, 2007). The helix-loop-helix is formed by an $\alpha$-helix, a $\mathrm{Ca}^{2+}$ binding loop composed of nine residues, and an additional $\alpha$-helix composed of eleven residues.(Gifford et al., 2007). The nine residues in the $\mathrm{Ca}^{2+}$ binding loop provide five ligands for $\mathrm{Ca}^{2+}$ coordination and two extra ligands are provided by the side chain of a Glu residue, resulting in the seven ligands that coordinate $\mathrm{Ca}^{2+}$ in the EF-loop (Gifford et al., 2007). In addition, a water molecule forming hydrogen bonds with one of the side chains of the loop completes the coordination sphere of $\mathrm{Ca}^{2+}$ (Gifford et al., 2007). These EF-loops are mostly composed of negatively charged amino acids Asp and Glu (Gifford et al., 2007), reflecting the preference of the EF-loop for less bulky carboxy side chains as 
shown in Table 1.1 (Gifford et al., 2007). The coordination of $\mathrm{Ca}^{2+}$ bound to EF-hand 3 and EF-hand 4 is shown in Fig. 1.4.

Table 1.1: Sequence of amino acid residues in canonical calcium binding loop. Adapted from (Gifford et al., 2007)

\begin{tabular}{|c|c|c|c|c|c|c|c|c|c|c|c|c|}
\hline $\begin{array}{l}\text { EF-loop } \\
\text { position }\end{array}$ & 1 & 2 & 3 & 4 & 5 & 6 & 7 & 8 & 9 & 10 & 11 & 12 \\
\hline $\begin{array}{l}\text { coordinati } \\
\text { ng ligand }\end{array}$ & $X$ & & $\begin{array}{l}\mathrm{Y} \\
\end{array}$ & & $\mathrm{Z}$ & & $-Y$ & & $-X$ & & & $-Z$ \\
\hline $\begin{array}{c}\text { Most } \\
\text { common }\end{array}$ & $\begin{array}{c}\text { Asp } \\
100 \\
\%\end{array}$ & $\begin{array}{l}\text { Lys } \\
29 \\
\%\end{array}$ & $\begin{array}{l}\text { Asp } \\
76 \\
\%\end{array}$ & $\begin{array}{c}\text { Gly } \\
56 \\
\%\end{array}$ & $\begin{array}{l}\text { Asp } \\
76 \\
\%\end{array}$ & $\begin{array}{c}\text { Gly } \\
96 \\
\%\end{array}$ & $\begin{array}{l}\text { Thr } \\
23 \\
\%\end{array}$ & $\begin{array}{l}\text { Ile } \\
68 \\
\%\end{array}$ & $\begin{array}{c}\text { Asp } \\
32 \\
\%\end{array}$ & $\begin{array}{l}\text { Phe } \\
23 \\
\%\end{array}$ & $\begin{array}{c}\text { Glu } \\
29 \\
\%\end{array}$ & $\begin{array}{l}\text { Glu } \\
92 \\
\%\end{array}$ \\
\hline $\begin{array}{c}\text { Also } \\
\text { frequently } \\
\text { observed }\end{array}$ & & $\begin{array}{l}\text { Ala } \\
\text { Gln } \\
\text { Thr } \\
\text { Val } \\
\text { Ile } \\
\text { Ser } \\
\text { Glu } \\
\text { Arg }\end{array}$ & Asn & $\begin{array}{l}\text { Lys } \\
\text { Arg } \\
\text { Asn }\end{array}$ & Asn & & $\begin{array}{l}\text { Phe } \\
\text { Lys } \\
\text { Gln } \\
\text { Tyr } \\
\text { Glu } \\
\text { Arg }\end{array}$ & $\begin{array}{l}\text { Val } \\
\text { Leu }\end{array}$ & $\begin{array}{l}\text { Ser } \\
\text { Thr } \\
\text { Glu } \\
\text { Asn } \\
\text { Gly } \\
\text { Gln }\end{array}$ & $\begin{array}{l}\text { Tyr } \\
\text { Ala } \\
\text { Thr } \\
\text { Leu } \\
\text { Glu } \\
\text { Lys }\end{array}$ & $\begin{array}{l}\text { Asp } \\
\text { Lys } \\
\text { Ala } \\
\text { Pro } \\
\text { Asn }\end{array}$ & Asp \\
\hline
\end{tabular}




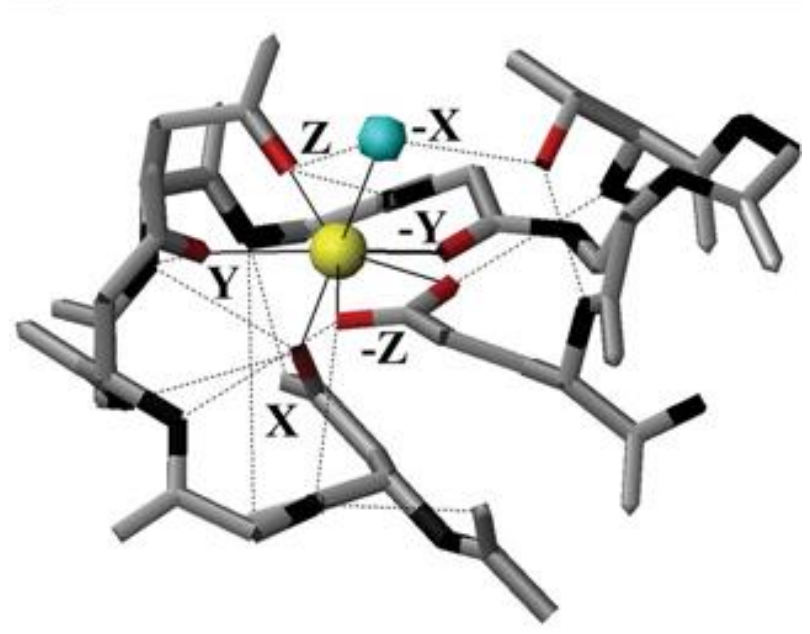

Fig. 1.3: $\mathrm{Ca}^{2+}$ coordination by the canonical EF-hand illustrating the pentagonal bipyramidal coordination of the $\mathrm{Ca}^{2+}$ ion (continuous thin lines) and the hydrogen bonding pattern in the loop (dashed lines). The backbone NH groups are shown in black, the sidechain oxygen atoms in red, the $\mathrm{Ca}^{2+}$ ion in yellow and the coordinating water molecule in blue (Gifford et al., 2007).
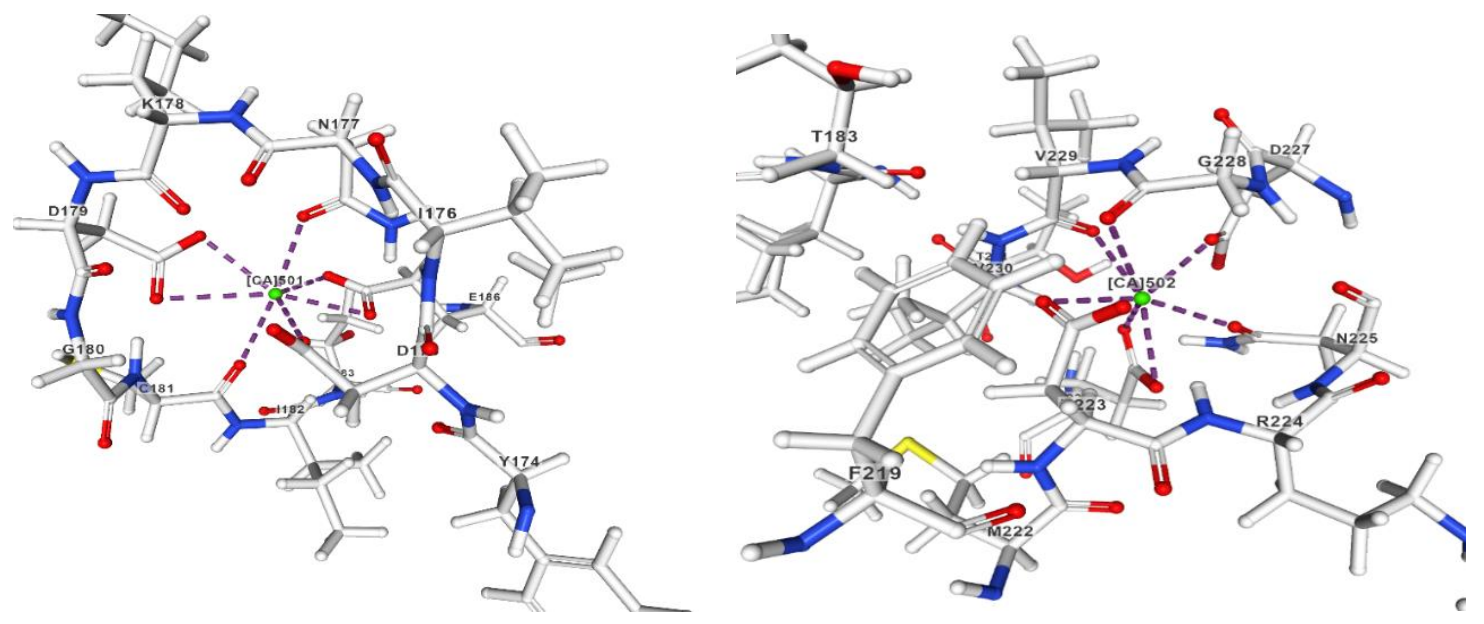

Fig. 1.4: Calcium coordination in EF-hand 3 (A) and EF-hand 4 (B) of neuronal calcium sensor DREAM, (PDB entry 2JUL).

\section{$1.4 \mathrm{Ca}^{2+}$ and neuronal calcium sensors in the brain}

The concentration of $\mathrm{Ca}^{2+}$ ions plays a crucial role in neuronal activity (Burgoyne $\&$ Weiss, 2001), since it modulates several processes such as neurotransmitter release, short term 
rapid modulations of channel function, long-term switches in gene expression (Burgoyne \& Weiss, 2001), regulation of Kv4.3 and Kv1.5 potassium channels, and regulation of presenilin processing (Pongs et al., 1993). The ability of $\mathrm{Ca}^{2+}$ to regulate such a variety of processes is due to its interactions with numerous $\mathrm{CPBs}$, which associate with other target proteins involved in the process mentioned before. (Burgoyne, R. D. \& Weiss, 2001)

\subsection{Neuronal Calcium Sensors.}

Neuronal calcium sensors (NCS) are expressed in retinal photoreceptors (Burgoyne \& Weiss, 2001) and in the brain (Burgoyne \& Weiss, 2001; Permyakov \& Kretsinger, 2011). The family of proteins is in charge of regulating a variety of physiological processes summarized in Fig. 1.5 and are linked to several pathological conditions such as Parkinson, Huntington and Alzheimer's disease (López-Hurtado et al., 2018). The family is composed of five different classes: A,B,C,D, and $\mathrm{E}$ referring to frequenin, visinin-like protein (VILIP), recoverins, guanylate cyclase (GC)-activating proteins (GCAPs), and Kvchannel-interacting proteins (KChIPs) (Burgoyne, R. D. \& Weiss, 2001). The main characteristics of the protein family are a tandem-like structural orientation of the $\mathrm{N}$ - and C- terminal domain and posttranslational myristoylation of the $\mathrm{N}$ - terminal residue. In addition, the sequence of the $\mathrm{N}$ - terminal domain shows a low sequence similarity, whereas 
the $\mathrm{C}$ - terminal domain sequence is homologous among the members of this family. (Permyakov. \& Kretsinger, 2011).
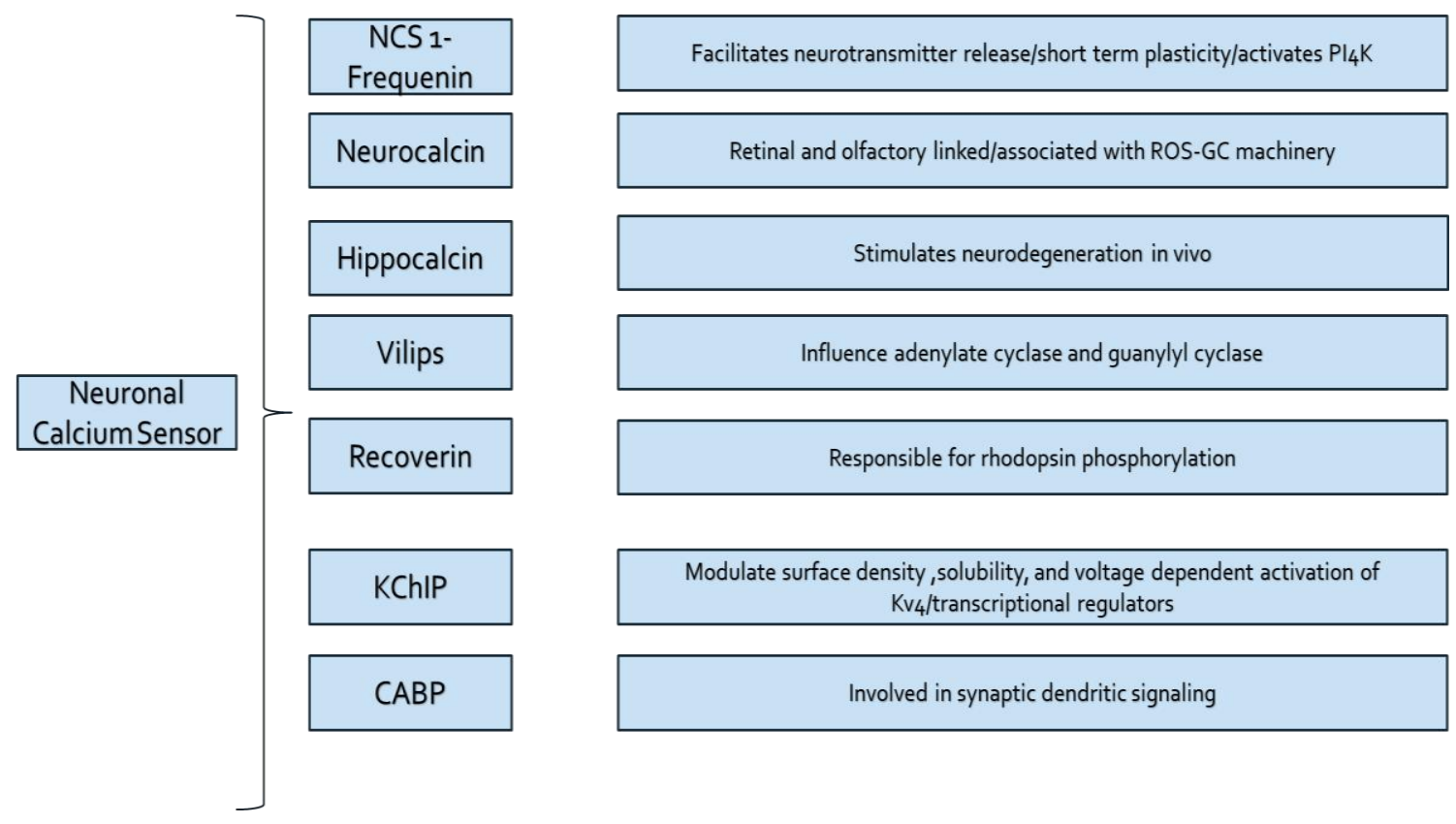

Fig. 1.5: Neuronal Calcium Sensor subfamilies classifications and main function Adapted from (Permyakov, E. A. \& Kretsinger, 2011)

Class A, frequenin (NCS-1), first appeared in yeast (Burgoyne \& Weiss, 2001) and it can bind up to three $\mathrm{Ca}^{2+}$ ions (Ames \& Lim, 2012) and a myristoyl group can be found at the $\mathrm{N}$ terminal allowing the protein to associate with lipid layers (Braunewell, Karl-Heinz \& Gundelfinger, 1999; Dason, Romero-Pozuelo, Atwood, \& Ferrús, 2012) . Class B, VILIPs, is formed by three members VILIP 1, 2 and 3. Visinin like proteins play a role in the regulation of the desensitization of signal cascades in retinal photoreceptors in a $\mathrm{Ca}^{2+}$ depended manner (Braunewell, Spilker, Behnisch, \& Gundelfinger, 1997). Class C is formed by one protein, recoverin, which has one human gene (Burgoyne \& Weiss, 2001). 
Recoverin is present in photoreceptor cells and its main function is to control light sensitivity by regulating the phosphorylation of rhodopsin kinase (Calvert, Klenchin, \& Bownds, 1995). Furthermore, as in the case of NCS-1, recoverin interacts with a myristoil group, which is responsible for inducing rhodopsin kinase inhibition in $\mathrm{Ca}^{2+}$ dependent manner (Calvert et al., 1995). Class D is formed by GCAPs 1, 2 and 3 (Burgoyne \& Weiss, 2001) and is expressed in the photoreceptors cells in the retina (Braunewell, Karl-Heinz \& Gundelfinger, 1999). The main function of GCAPs is to activate or inhibit guanylyl cyclase in the retina (Burgoyne, Robert D. \& Haynes, 2012). Class E is formed by KChIP 1, 2 and 3 (Burgoyne, R. D. \& Weiss, 2001). They interact with the Kv4 family of A-type potassium channels (Burgoyne \& Haynes, 2012) and may participate in regulating voltagegated $\mathrm{Ca}^{2+}$ channel signaling (Burgoyne \& Haynes, 2012) . The KChIP 1-4 family bind with the cytosolic $\alpha$-subunit of potassium channels, so called T1 domain (Ling et al., 2000), forming a cross-shaped octamer (Findeisen, Hura, Minor, \& Pioletti, 2006), Pioletti et al. determined an X-ray structure of KChIP1 in complex with potassium channel showing that each KChIP1 monomer interacts with two Kv4.3 T1 domains, forming an octamer which is composed by four KChIP1s and four Kv4.3 subunits. (Findeisen et al., 2006), The first KCHIP1- Kv4.3 binding site is formed by hydrophobic interactions among the hydrophobic residues in the $\mathrm{N}$ terminal of Kv4.3 and a hydrophobic cavity on the surface of KChIP1, so called Site 1 is composed of amino acids 2-22 from Kv4.3. The second binding site is between the $\mathrm{N}$ terminal of KChIP1 and a T1 domain loop, so called Site 2, and corresponds to amino acids 70-90 from the T1 domain (Findeisen et al., 2006). The class $\mathrm{E}$ member $\mathrm{KChIP} 2$ is present in cardiomyocytes and it has been proposed to interact with presenilin and have a role in the ryanodine receptor-mediated $\mathrm{Ca}^{2+}$-induced 
$\mathrm{Ca}^{2+}$ release (Bähring, 2018). The third class E member, KChIP3 also known as DREAM or calsenilin interacts with DNA and regulates gene expression of genes involved in pain sensing such prodynorphin gene; it activates presenilin, and modulates kinetics of $\mathrm{Kv}$ channels through interactions with the T1 domain. (Burgoyne, Robert D. \& Haynes, 2012).

\subsection{Downstream Regulatory Element Antagonist Modulator.}

Downstream Regulatory Element Antagonist Modulator (DREAM) is a member of the NCS family, which belongs to the potassium voltage channel subfamily (Carrión, Link, Ledo, Mellström, \& Naranjo, 1999). The DREAM protein is composed of 256 amino acids and contains $4 \mathrm{EF}$ hands as shown in Fig. 1.6. and 1.7. The EF hand 1 does not bind any metal due to the presence of a proline residue within the metal binding loop, EF hand 2 binds to $\mathrm{Mg}^{2+}$ with an equilibrium dissociation constant of around $13 \mu \mathrm{M}$ (Masanori Osawa et al., 2005), and $\mathrm{EF}$ hand 3 and 4 bind to $\mathrm{Ca}^{2+}$ with an affinity of around $1 \mu \mathrm{M}$ (Masanori Osawa et al., 2005). DREAM also interacts with small hydrophobic molecules such as 1,8 ANS and arachidonic acid with an affinity modulated by $\mathrm{Ca}^{2+}$ binding to the protein. (Gonzalez \& Miksovska, 2014). The NMR structure of the truncated form (residue 76 to 256) of $\mathrm{Ca}^{2+}$ bound DREAM is shown in Fig. 1.6. Ten $\alpha$-helix were identified in the truncated form with helices 2-5 forming EF-hand 1 and EF-hand 2 and helices 6-9 forming EF-hand 3 and EF-hand 4. (Lusin, Vanarotti, Li, Valiveti, \& Ames, 2008).

Previous studies have shown that DREAM is involved in several biological processes. Ooi et al.(2008) have shown that DREAM is able to regulate learning and memory by inhibiting the activity of cAMP Response Element Binding Protein (CREB). In the absence of $\mathrm{Ca}^{2+}$, DREAM binds to DRE sequence, inhibiting the expression of genes regulated by CREB/CREM complex. In the presence of $\mathrm{Ca}^{2+}$, DREAM dissociates from DNA allowing 
the expression of CREB/CREM genes (Ooi \& Wood, 2008) . Furthermore, in the absence of $\mathrm{Ca}^{2+}$, DREAM interacts with CREB and CREM (cAMP Response Element Modulator) inhibiting cAMP-mediated transcriptional activation (Ooi \& Wood, 2008).

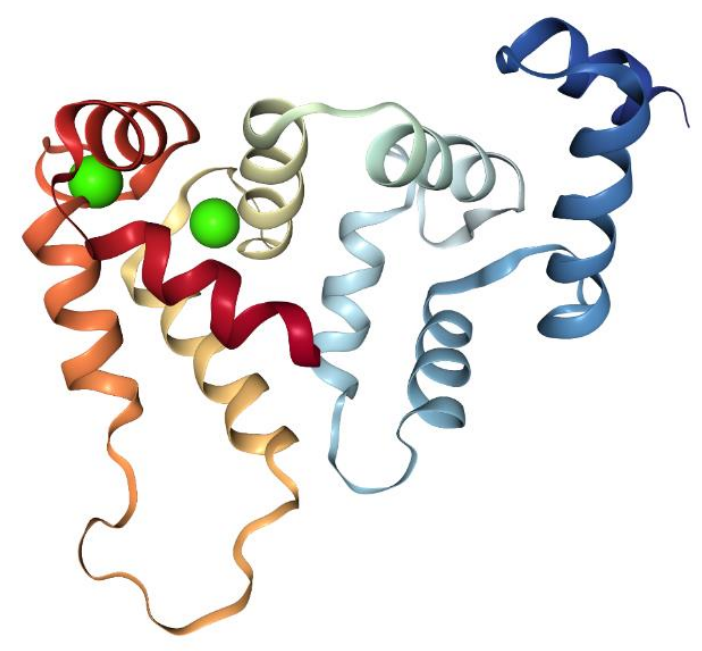

Fig. 1.6: DREAM structure determined by NMR. $\alpha$-helices are shown as ribbons with the $\mathrm{N}$-terminal domain shown in blue and the $\mathrm{C}$-terminal domain in red, $\mathrm{Ca}^{2+}$ ions are represented as green spheres. (PDB entry 2JUL)

\begin{tabular}{|c|c|c|c|c|c|}
\hline 10 & 20 & $3 \underline{0}$ & $4 \underline{0}$ & $5 \underline{0}$ & $6 \underline{0}$ \\
\hline MQRTKEAVKA & SDGNLLGDPG & RIPLSKRESI & KWQRPRFTRQ & ALMRCCLIKW & ILSSAAPQG $\bar{S}$ \\
\hline 70 & 80 & 90 & 100 & 110 & 120 \\
\hline DSSDSELELS & TVRHQPEGL $\bar{D}$ & QLQAQTKFTK & KELQSLYRGF & KNECPTGLVD & EDTFKLIYSQ \\
\hline 130 & 140 & 150 & 160 & 170 & 18 \\
\hline FFPQGDATTY & AHFLFNAFDA & DGNGAIHFED & FVVGLSILL $\bar{R}$ & GTVHEKLKWA & FNLYDINKDG \\
\hline 190 & 200 & 210 & 220 & 230 & 24 \\
\hline CITKEEMLAI & MKSIYDMMGR & HTYPILREDA & PLEHVERFF' & KMDRNQDGVV & TIDEFLETCQ \\
\hline 250 & & & & & \\
\hline KDENIMNSMQ & LFENVI & & & & \\
\hline
\end{tabular}

Fig. 1.7: Amino acid sequence of DREAM. The sequence corresponding to the individual EF-hands is shown in green, red, blue and yellow. 
Furthermore, the binding of DREAM to DRE sequence is also involved in the transcriptional repression of prodynorphin genes related to pain sensitivity and c-fos, cjunk, and hrk genes related to cell proliferation. This ability of DREAM to bind to DNA makes it the only known $\mathrm{CBP}$ to regulate gene expression in a calcium dependent manner (Carrión et al., 1999; Cheng \& Penninger, 2004).

The DREAM protein like all members of KChIP proteins, modulates A-type potassium currents by interacting with Kv4.3 potassium channels (Ling et al., 2000). Even though the structure for KChIP1 in complex with potassium voltage channel is the only that has been determined (Findeisen et al., 2006), the KChIP family has a high sequence similarity and the amino acids involved in the stabilization of the KCHIP1-Kv4.3 interactions are conserved throughout the KChIP family (Ling et al., 2000). Therefore, analogous interactions are expected between all KChIPs and potassium voltage channels.

The importance of DREAM in neurological and neuropathological processes is clearly demonstrated by the fact that DREAM is implicated in several neurological diseases such as Alzheimer's disease, Huntington and Parkinson disease (López-Hurtado et al., 2018). Lilliehook et al. (1998) reported that DREAM interacts with the presenilin unit of the $\gamma$ secretase complex and enhances the cleavage of amyloid precursor proteins into a $\beta 42$ plaques. The plaques are commonly found post-mortem as a diagnostic feature of patients with Alzheimer's disease (Lilliehook et al., 1998).

The precise mechanism of how $\mathrm{Ca}^{2+}$ modulates DREAM interaction with DNA and other intracellular partner remains unknown. This protein has been shown to undergo an oligomerization transition upon binding of $\mathrm{Ca}^{2+}$ (Masanori Osawa et al., 2005; Yu et al., 2007). In the absence of $\mathrm{Ca}^{2+}$, DREAM presents a monomer-tetramer equilibrium whereas 
upon $\mathrm{Ca}^{2+}$ binding to the $\mathrm{C}$ - terminal domain, the protein forms a stable dimer (Carrión et al., 1999; Gonzalez \& Miksovska, 2014; Lusin et al., 2008). Previous studies have shown that DREAM interacts with potassium channels as a monomer (Ping Liang et al., 2009; Yu et al., 2007) in both the $\mathrm{Ca}^{2+}$ bound and $\mathrm{Ca}^{2+}$ free form, with presenilin and calmodulin as a dimer, and with DNA as a monomer or tetramer (Carrión et al., 1999) suggesting that changes in the protein oligomerization are important for $\mathrm{Ca}^{2+}$ signaling mechanism.

\subsection{Objectives}

\section{Objective 1:}

Zinc is a divalent cation, which possesses a filled d orbital, which means that it does not participate in redox reaction. Because of this $\mathrm{Zn}^{2+}$ can be used as a cofactor in biological reaction which do not required the presence of a metal, which can be involved in redox reactions [JM1]

Previous studies have shown that $\mathrm{Zn}^{2+}$ is able to bind to $\mathrm{Ca}^{2+}$ buffer proteins such as parvalbumin with a Kd of $5 \times 10^{-5}$ M. (Permyakov, E. A. \& Kretsinger, 2011) Furthermore, $\mathrm{Zn}^{2+}$ is also able to bind to calmodulin albeit weakly with a dissociation constant od $10^{-3}$ M (Warren, Guo, \& Tang, 2007). The metal binding site in proteins, which bind to $\mathrm{Zn}^{2+}$ usually, involve His Glu Asp and Cys. Some of the biological functions of $\mathrm{Zn}^{2+}$ involve neuronal growth and plasticity indicating a similar role as that of $\mathrm{Ca}^{2+}$. Recently[JM2] published study by Permyakov et al. have shown that $\mathrm{Zn}^{2+}$ binds to a member of neuronal calcium sensor family, recoverin with an affinity of $7.0 \mu \mathrm{M}$ (Permyakov, S. E. et al., 2003). Considering a high sequence and structural homology between members of NCS family, it is proposed that DREAM can also serve as an intracellular target for $\mathrm{Zn}^{2+}$. With this in 
mind, we conducted fluorescence studies and circular dichroism studies to elucidate zinc binding to DREAM and its impact on protein stability.

\section{Objective 2:}

Even though results from several research groups have addressed structural and functional properties of DREAM, the molecular mechanism of calcium triggered signaling and allosteric regulation with intracellular partners remains unknown for DREAM and other members of the neuronal calcium sensor family. The goal of my thesis was to provide insight into the $\mathrm{Ca}^{2+}$ triggered dimerization process of DREAM. Considering the high sequence homology of the $\mathrm{C}$ - terminal domain among neuronal calcium sensors, the results obtained in my study can be applied to other potassium channel interacting proteins and other members of the neuronal calcium sensor family.

Previous studies by the Ames group suggested that hydrophobic interactions between Leu residues (Leu155, Leu159 and Leu251) stabilize the dimeric form of the $\mathrm{Ca}^{2+}$ bound DREAM dimer. However, the unpublished computational and polarization data from our group indicate that two salt bridges between individual monomers (Arg 200, Arg 207, and Glu 103) also contribute to the protein stability. To study the DREAM dimerization mechanism, we designed a chimeric DREAM-NCS 1 protein. Taking into account that the NCS1 protein does not form a dimer in the $\mathrm{Ca}^{2+}$ bound form, we have replaced residues in the loop connecting EF-hand 3 and EF-hand 4 with the sequence found in NCS1. In addition, hydrophobic residues Leu 157 and Leu 158 have been replaced by alanine residue

corresponding to the analogues residues in neuronal calcium sensor 1 (Thr 157 and Ser 
158) which does not form dimers. The alignment of the sequence of DREAM WT and DREAM-NCS1 chimeric protein is shown in Figure 1.8. The structural properties of the chimeric protein were investigated using steady state and time resolved fluorescence and circular dichroism spectroscopy. In addition, interaction of the chimeric protein with the peptides mimicking the DREAM binding sites in $\mathrm{T} 1$ domain of $\mathrm{Kv}$ channel were characterized. 


\section{MATERIALS AND METHODS}

\subsection{Chemicals and reagents}

Reagents and solvents $\mathrm{CaCl}_{2}, \mathrm{ZnCl} 2, \mathrm{MgCl}_{2}$, EDTA and EGTA, as well as the reagents required for the protein expression and purification were purchased from Sigma-Aldrich or Fischer Scientific and were of analytical grade. The hydrophobic fluorescent probe 1,8ANS, was purchased from Invitrogen. 1,8-ANS, stock was prepared in ultrapure water $\left(18.2 \mathrm{M} \Omega\right.$ ) and stored at $-20^{\circ} \mathrm{C}$ and the concentration was determined spectrophometrically using the extinctions coefficients listed in Table 2.1.

Fluorescently labeled peptides Site 1 and Site 2 were purchased from Thinkpeptides, the stocks were prepared in $20 \mathrm{mM}$ Tris buffer $\mathrm{pH} 7.4$ and the concentration was determined spectrophotometrically using the extinction coefficients listed in Table 2.1.

\subsection{Protein purification and isolation.}

Recombinant mouse DREAM (65-256) protein with a His tag at the N-terminus was expressed in E. coli (DE 21) (Invitrogen). Cells were grown in Terrific Broth (TB) media at $37^{\circ} \mathrm{C}$ and $250 \mathrm{rpm}$ speed for $12 \mathrm{~h}$. Isopropyl $\beta$-D-1-thiogalactopyranoside (IPTG) was added when optical density at $600 \mathrm{~nm}$ (OD) reached 0.75 and cells were grown for additional $12 \mathrm{~h}$. Subsequently, cells were harvested by centrifugation at $4{ }^{\circ} \mathrm{C}$ and $5000 \mathrm{rpm}$ for 20 min (ST 16R centrifuge, Thermal Scientific) and treated with lysis buffer overnight. The composition of the lysis buffer is $20 \mathrm{mM}$ Tris- $\mathrm{HCl}, \mathrm{pH} 8.0,300 \mathrm{mM} \mathrm{NaCl}, 1 \mathrm{mM} \beta$ mercaptoethanol, $20 \%$ glycerol, 1mM phenylmethyl sulfonyl fluoride (PMSF), 0.2\% 
Tween 20, $20 \mu \mathrm{g} / \mathrm{mL}$ DNase I, $5 \mu \mathrm{g} / \mathrm{mL}$ lysozyme, and $5 \mathrm{mM} \mathrm{MgCl}_{2}$ and $\mathrm{pH} 8.0$. Cells were broken through sonication using a sonic dismembrator (model 100, Fisher Scientific) for 40 intervals of 20 seconds with 2 min of resting on ice between each interval. Disrupted cells were centrifuged for 4 hours at $5000 \mathrm{rpm}$ and supernatant was collected. Supernatant was then passed through a Ni-NTA affinity column (Quiagen) equilibrated with buffer A containing $20 \mathrm{mM}$ Tris- $\mathrm{HCl}, \mathrm{pH} 8.0,300 \mathrm{mM} \mathrm{NaCl}, 1 \mathrm{mM} \beta$-mercaptoethanol, and 10\% glycerol. The column was washed with an increasing concentration of imidazole in buffer A $(10 \mathrm{mM}, 20 \mathrm{mM}$ and $40 \mathrm{mM})$ until the OD of the eluate at 280 was less than 0.02 . Finally, and the protein was eluted with buffer A containing $250 \mathrm{mM}$ imidazole. Protein was then dialyzed against a $20 \mathrm{mM}$ Tris buffer $\mathrm{pH} 8.0$ to remove residual imidazole and passed through an anion exchanged di-ethyl-amino-ethyl (DEAE) column, which was consecutively washed with $20 \mathrm{mM}$ Tris buffer $\mathrm{pH} 8.0$ containing an increasing $\mathrm{NaCl}$ concentration $(20 \mathrm{mM}, 40 \mathrm{mM}$, and $80 \mathrm{mM} \mathrm{NaCl})$. The protein was eluted with $200 \mathrm{mM}$ $\mathrm{NaCl}$ in $20 \mathrm{mM}$ Tris buffer $\mathrm{pH} 8.0$ and dialyzed against $20 \mathrm{mM}$ TRIS pH 7.4 overnight. The purity of the protein was determined using SDS-PAGE electrophoresis and the $\mathrm{Ca}^{2+}$ binding properties were characterized using emission spectroscopy and circular dichroism spectroscopy as described below.

\subsection{UV-VIS absorption}

The presence of aromatic amino acid residues with conjugated electrons, Trp, Phe and Tyr, peptides and proteins the ability to absorb light in the UV range from $250 \mathrm{~nm}$ to $300 \mathrm{~nm}$. 
These conjugated systems allow to observe $\pi->\pi^{*}$ electronic transitions upon excitation as shown in the Jablonski diagram (Figure 2.1)

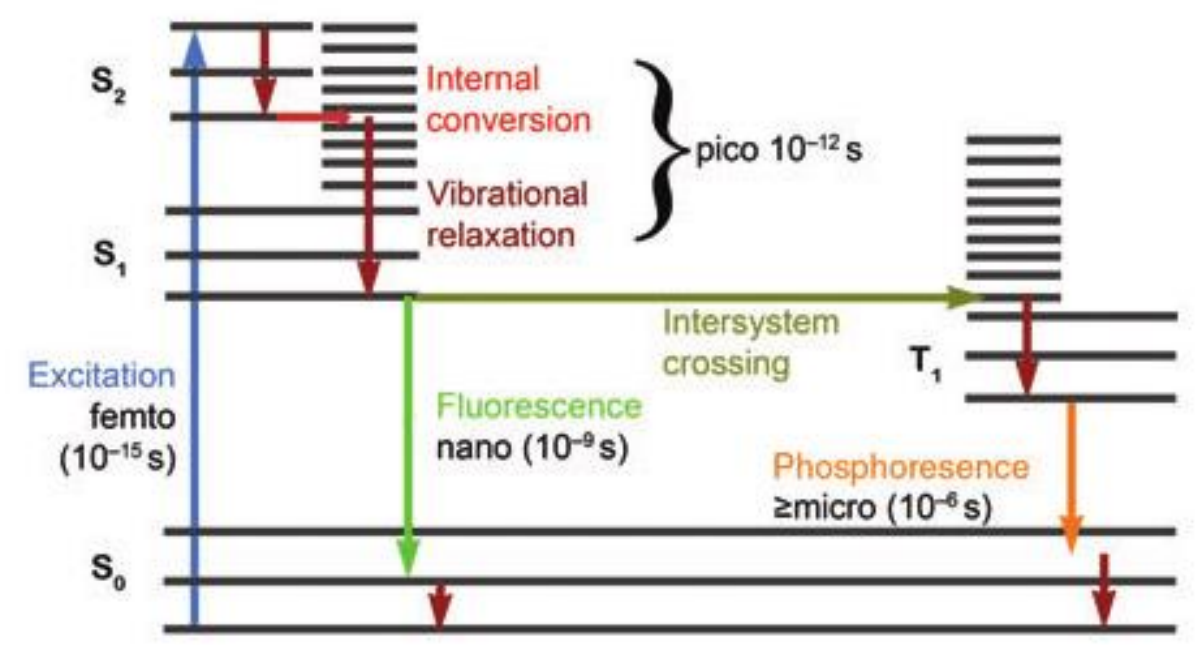

Fig. 2.1: Representation of the Perrin-Jablonski diagram. The arrows indicate the transition between the different electronic states. Radiative processes are shown, absorption is represented by the blue arrow, emission is represented by the bright green arrow and phosphorescence is represented by the orange arrow. The non-radiative processes, such as internal conversion, intersystem crossing and vibrational relaxation are shown in red, flat green and maroon respectively.

The absorbance (A) is determined as a ratio of the intensity of light before (Io) and after (I) it passes through an optical cell according to (Eq 1).

$$
A=\log \frac{I_{0}}{I}
$$

based on the absorbance value, the concentration of the protein sample can be determined using Beers Lambert Law (Eq. 2).

$$
A=\varepsilon b c
$$


where $\varepsilon$ is the extinction coefficient in $\mathrm{cm}^{-1} \mathrm{M}^{-1}, \mathrm{~b}$ is the pathway in $\mathrm{cm}$ and $\mathrm{c}$ is the concentration in mol $\mathrm{L}^{-1}$. The values of extinction coefficients used in this study are summarized in Table 2.1.

Table 2.1: Extinction coefficient values used in this study

\begin{tabular}{|c|c|c|c|}
\hline & $\lambda \max (\mathrm{nm})$ & $\begin{array}{c}\text { Extinction coefficient }\left(\mathrm{cm}^{-}\right. \\
\left.{ }^{1} \mathrm{M}^{-1}\right)\end{array}$ & Source \\
\hline DREAM WT & 280 & 19000 & $\begin{array}{c}\text { (Azam \& } \\
\text { Miksovska, 2019) }\end{array}$ \\
\hline DREAM-NCS 1 & 280 & 19000 & $\begin{array}{c}\text { (Azam \& } \\
\text { Miksovska, 2019) }\end{array}$ \\
\hline $1,8-\mathrm{ANS}$ & 350 & 5000 & (Stryer, 1965) \\
\hline Kv 4.3 Site 1 & 493 & 80000 & $\begin{array}{c}\text { (Azam \& } \\
\text { Miksovska, 2019) }\end{array}$ \\
\hline Kv 4.3 Site 2 & 493 & 75000 & $\begin{array}{c}\text { (Azam \& } \\
\text { Miksovska, 2019) }\end{array}$ \\
\hline
\end{tabular}

\subsection{Steady state emission}

The emission spectrum is the measure of the light intensity emitted by a sample as a function of wavelength, after the sample has been excited at a specific wavelength (Jameson, 2014; Lakowicz, 2006). The Trp residue is a commonly used intrinsic probe in proteins as its emission properties can be used to monitor protein tertiary structure changes due to its sensibility to the surrounding environment, (Jameson, 2014)

The DREAM protein has a unique Trp residue in position 169 located in a hydrophobic cavity (Lusin et al., 2008), which was used to monitored changes in the protein tertiary structure upon $\mathrm{Ca}^{2+}$ association to the protein. The Trp emission spectra were recorded 
using PC1 fluorimeter. The samples were excited with a $280 \mathrm{~nm}$ output from the Xe lamp and emission was collected in 90-degree orientation from $300 \mathrm{~nm}$ to $470 \mathrm{~nm}$. The samples for emission measurements contained $10-\mu \mathrm{M}$ protein solubilized in $20 \mathrm{mM}$ Tris buffer $\mathrm{pH}$ 7.4. The sample was placed in a $0.1 \times 1.0 \mathrm{~cm}$ or $0.2 \times 1.0 \mathrm{~cm}$ quartz cuvette. The apo, $\mathrm{Mg}^{2+}$, $\mathrm{Ca}^{2+}$ and $\mathrm{Mg}^{2+} \mathrm{Ca}^{2+}$ bound protein was prepared by adding 5 mM EDTA,5 mM EGTA, 1 $\mathrm{mM} \mathrm{MgCl} 2$ and/or $1 \mathrm{mM} \mathrm{CaCl}_{2}$ to the protein samples.

\subsection{Fluorescence lifetime}

Fluorescence lifetime of fluorophore $(\tau)$ is the measure of how much time the molecule spends in the excited state, corresponding to the time between absorption and emission (Jameson, 2014), and is commonly expressed using Eq. 3, where $\tau$ is the lifetime in ns, $\mathrm{k}_{\mathrm{rad}}$ is the rate constant for radiative processes and $\mathrm{k}_{\text {nonrad }}$ is the rate constant for nonradiative processes.

$$
\tau=\frac{1}{\text { krad }+ \text { knonrad }}
$$

The information of the lifetime of intrinsic or extrinsic fluorescence probes in protein provide additional information and structural and dynamic properties in protein and are important for interpreting other parameters such as lifetime and anisotropy (Jameson, 2014). Fluorescence lifetime can be measured using the time domain or the frequency domain approach (Jameson, 2014). In the time domain approach the sample is excites with a short laser pulse and the change in intensity is measured as a function of time (Jameson, 2014). On the other hand, in the frequency domain approach, the sample is excited using a continuous light source modulated at different high frequencies (20 MHz to $200 \mathrm{MHz})$ ) 
in a sinusoidal manner, as a result of the excitation the sample, the emitted light shown a frequency phase shift and amplitude modulation with respect to the excitation source modulated emission light (Jameson, 2014; Lakowicz, 2006). The lifetime can be determined by analyzing the experimental data using several models such as sum of multiple exponential decay, Gaussian distribution, Lorents distribution etc. (Jameson, 2014). The lifetime data presented in this study were measured in the frequency domain using Chrono FM fluorometer (ISS, Chapagain Illinois)

The samples for Trp fluorescence lifetime measurements contained $20 \mu \mathrm{M}$ protein in 20 $\mathrm{mM}$ Tris buffer $\mathrm{pH}$ 7.4. The apo, $\mathrm{Mg}^{2+}, \mathrm{Ca}^{2+}$ and $\mathrm{Mg}^{2+} \mathrm{Ca}^{2+}$ bound proteins were prepared by adding $5 \mathrm{mM}$ EDTA, $5 \mathrm{mM}$ EGTA, $1 \mathrm{mM} \mathrm{MgCl} 2$ and/or $1 \mathrm{mM} \mathrm{CaCl}_{2}$ into proteins samples. The compound 2.5-diphenyl-oxazole (PPO) with the lifetime of $1.4 \mathrm{~ns}$ was used as a reference. The sample was excited with $280 \mathrm{~nm}$ laser diode and the emission intensity was collected using a $300 \mathrm{~nm}$ long pass filter (Andover). The plots of phase modulation and phase shift as a function of modulation frequency were fitted using a three exponential decays model. The quality of the fit was judged by a $\chi^{2}$ value and residual.

The samples for measuring emission lifetime of DREAM in the presence of 1,8-ANS contained $20 \mu \mathrm{M}$ protein in $20 \mathrm{mM}$ Tris buffer $\mathrm{pH} 7.4$ and $20 \mu \mathrm{M}$ 1,8-ANS. The apo, $\mathrm{Mg}^{2+}$, $\mathrm{Ca}^{2+}$ and $\mathrm{Mg}^{2+} \mathrm{Ca}^{2+}$ bound proteins were prepared by adding $5 \mathrm{mM}$ EDTA, 5 mM EGTA, $1 \mathrm{mM} \mathrm{MgCl} 2$ and/or $1 \mathrm{mM} \mathrm{CaCl}_{2}$ into proteins samples. The samples were placed in a $0.1 \times 1.0 \mathrm{~cm}$ or $0.2 \times 1.0 \mathrm{~cm}$ quartz cuvette and the output of $305 \mathrm{~nm}$ diode was used for the excitation. The emission intensity was collected using a $400 \mathrm{~nm}$ long pass filter (Andover Corp). The plots of phase modulation and phase shift as a function of modulation frequency 
were fitted using a three exponential decays model. The quality of the fit was judged by a $\chi^{2}$ value and residual.

\subsection{Anisotropy}

Anisotropy measurements allow to determine rotational mobility of a fluorophore by monitoring the ratio of the emitted light using different orientation of polarizers placed in the excitation and emission path according to Eq 4. (Jameson, 2014).

$$
A=\frac{I_{I I}-I_{\perp}}{I_{I I}+2 I_{\perp}}
$$

where $A$ represents anisotropy and $\mathrm{I}_{\mathrm{II}}$ and $\mathrm{I}_{\perp}$ represent the parallel and perpendicular orientation of the polarizers. In general, the excitation light passes through a polarizer placed in the excitation path and only fluorophore molecules that have a transition dipole

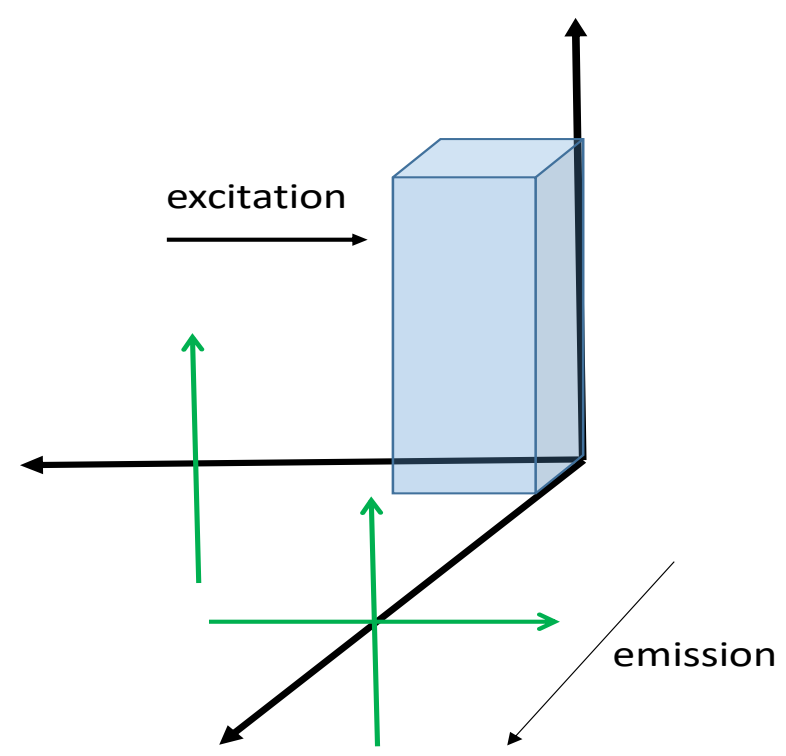

Fig. 2.2: Position of the polarizers for the steady-state anisotropy measurements. The Direction of the propagation of the excitation light and collected emitted light are shown as thin black arrows, the orientation of the polarizer placed in the excitation and emission path are shown in green. (Adapted from Jameson 2004). 
moment aligned with the electric field of the excitation light are excited. The polarization of the emitted light corresponds to the orientation of the transient dipole moment of the excited molecule at the time of light emission (Lakowicz, 2006). For small molecules that freely rotate in the solution, the emitted light is depolarized, whereas light emitted by molecules or molecules trapped in a membrane or a solid like environment emit light polarized in the orientation analogous to the polarization of the excitation light. (Jameson, 2014) A second polarizer placed in the path of the emitted light is in a parallel or perpendicular orientation with respect to the polarizer placed in the excitation path and the emission intensity is collected. As anisotropy values are usually proportional to the size of the fluorescent molecule, anisotropy represent a convenient approach to characterized binding of small fluorescent molecules to proteins. By measuring anisotropy as a function of an increasing concentration of the protein, the binding isotherm for fluorophore association to the protein can be constructed and the equilibrium association or dissociation constants can be determined by analyzing the experimental data using an appropriate model.

Here we used the anisotropy approach to measure the dissociation constant for binding of fluorescent labeled peptides that mimic DREAM binding sites in the T1 domain of potassium voltage channels, so called site 1 and site 2 . The site 1 corresponds to the residues 2 to 22 of the T1 domain (FITC-AAGVAAWLPFARAAAIGWMPV)) and the site 2 corresponds to the residues 70 to 90 of the T1 domain (FITCLLGSTEKEFFFNEDTKEYFFD). The peptides were labeled by a fluorescent probe fluorescein isothiocyanate (FITC) (Scheme 2.1) covalently attached the peptide Nterminal. 


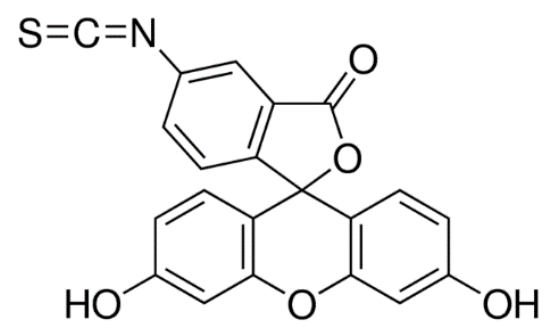

Fig. 2.3: Structure of FITC

Peptides were solubilized in $20 \mathrm{mM}$ Tris buffer $\mathrm{pH} 7.8$ and anisotropy was measured using $390 \mathrm{~nm}$ excitation light. The emission was collected through a long pass $500 \mathrm{~nm}$ filter placed in the emission light pathway. Subsequently small aliquots of DREAM WT or DREAM-NCS1 protein were added and anisotropy values were recorded. Each value of anisotropy corresponds to an average value determined for 10 measurements. The values of the anisotropy change were plotted as a function of protein concentration and the titration curves were analyzed using quadratic equation (Eq. 5) and assuming a single binding site for each peptide.

$$
\Delta \mathrm{A}=\frac{\left(\mathrm{K}_{\mathrm{d}}+\left[\mathrm{P}_{\mathrm{t}}\right]+\left[\mathrm{L}_{\mathrm{t}}\right]\right)-\sqrt{\left(\mathrm{K}_{\mathrm{d}}+\left[\mathrm{P}_{\mathrm{t}}\right]+\left[\mathrm{L}_{\mathrm{t}}\right]\right)^{2}-4\left[\mathrm{P}_{\mathrm{t}}\right]\left[\mathrm{L}_{\mathrm{t}}\right]}}{2 c}
$$

where $\Delta \mathrm{A}$ is the change in anisotropy, $\mathrm{K}_{\mathrm{d}}$ is the equilibrium dissociation constant, $\mathrm{P}_{\mathrm{t}}$ is the total concentration of protein in the sample, $\mathrm{L}_{\mathrm{t}}$ is the total ligand concentration of $0.5 \mu \mathrm{M}$, and $\mathrm{c}$ is the proportionality constant. 


\subsection{Circular Dichroism}

Circular dichroism (CD) is a widely used technique to study protein secondary structure as well as protein stability (Greenfield, 2007). In CD measurements, difference in the absorbance of the right and left circularly polarized light in the far ultraviolet (UV) and near UV spectrum is determined as chiral chromophore have a different extinction coefficient for the left and right circularly polarized light. (Greenfield, 2007). The CD spectra of protein in the far UV (190 $\mathrm{nm}$ to $250 \mathrm{~nm})$ provides information of the secondary structure of proteins major secondary structure elements, $\alpha$-helices, $\beta$-sheets and random coil, have a distinct CD spectrum as shown in Fig. 2.3.

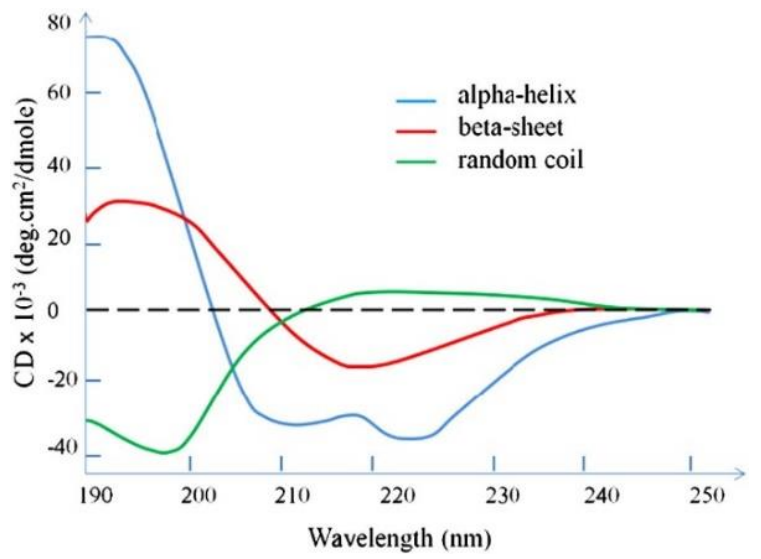

Fig. 2.4: Typical CD spectra, showing the three major secondary structures of proteins, $\alpha$-helix, $\beta$-sheet and random coil with distinctive peak at specific wavelengths. Adapted from Wei et al. (Wei, Thyparambil, \& Latour, 2014)

For instance, $\alpha$ helical structures show a strong positive peak at $192 \mathrm{~nm}$ and two negative peaks at 208 and $222 \mathrm{~nm}$. In the case of $\beta$ sheets, a negative peak at $218 \mathrm{~nm}$ and a positive peak at $196 \mathrm{~nm}$ are observed whereas random coils show only a very week CD signal (Greenfield, 2007). The monitoring of CD spectra in the near UV region are less common, 
however these data can provide information about structural changes in the environment of aromatic residues Phe, Tyr and Trp.

The samples for $\mathrm{CD}$ measurement contained $20 \mu \mathrm{M}$ protein in $20 \mathrm{mM}$ Tris buffer $\mathrm{pH} 7.4$ placed in a $0.1 \mathrm{~mm} \times 1 \mathrm{~cm}$ quartz cuvette. The apo, $\mathrm{Mg}^{2+}, \mathrm{Ca}^{2+}$ and $\mathrm{Mg}^{2+} \mathrm{Ca}^{2+}$ bound DREAM was prepared by adding $5 \mathrm{mM}$ EDTA,5 mM EGTA, $1 \mathrm{mM} \mathrm{MgCl} 2$ and/or $1 \mathrm{mM}$ $\mathrm{CaCl}_{2}$ to the protein samples. The data were collected from 190 to $260 \mathrm{~nm}$ using a J-810 Jasco CD spectrometer.

\subsection{Isothermal Calorimetry}

Isothermal calorimetry is a widely used analytical technique, which provides thermodynamic parameters such as $\mathrm{K}_{\mathrm{eq}}, \Delta \mathrm{G}, \Delta \mathrm{H}$ and $\Delta \mathrm{S}$ using $\mathrm{Eq}$ (6) and (7)

$$
\begin{aligned}
& \Delta G=-R T \ln K \\
& \Delta G=\Delta \mathrm{H}-\mathrm{T} \Delta \mathrm{S}
\end{aligned}
$$

It determines the heat in a reaction process proportional to the molar enthalpy change associated with the process and the amount of complex formed. 


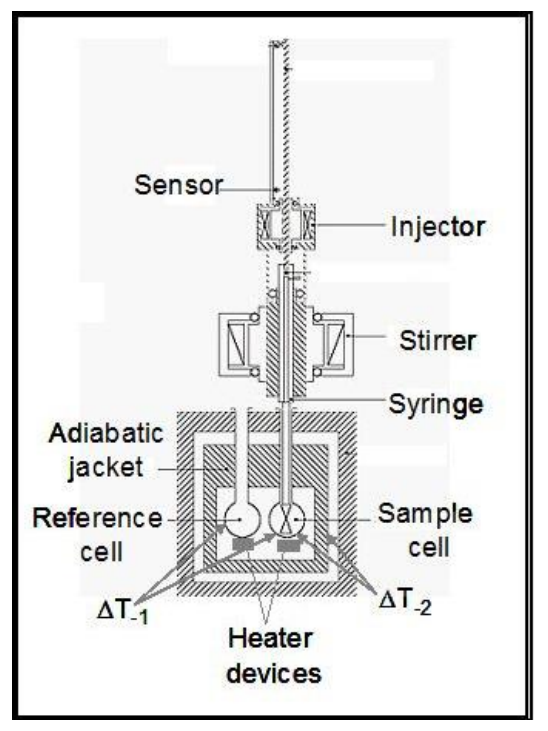

Fig. 2.5: ITC instrumentation. Adapted from (Martinez et al., 2013)

The ITC experiments were performed employing a VP-ITC MicroCalorimeter (MicroCal LLC, Northampton MA). The ITC instrument contains an adiabatic jacket with a reference and a sample cell, where the titration occurs. The sensor measures the amount of heat needed to keep the sample and reference cell temperature constant with every addition of ligand, providing a heat signal as a function of time. The heat signal is integrated and plotted as a function of molar ratios of the ligand and protein. The ITC data are then analyzed using fitting models in Origin 7 software to calculate thermodynamic parameters including number of binding sites (n), equilibrium association constant $(\mathrm{Ka})$, reaction enthanlpy change $(\Delta \mathrm{H})$ and reaction entropy change $(\Delta \mathrm{S})$ (MicroCal, LLC, Northampton, USA). In the experiments presented in Chapter 3, the experimental data were fitted to one sequential binding site model. 


\section{INTERACTIONS OF DREAM WITH $\mathrm{Zn}^{2+}$ ION.}

\subsection{Introduction}

Zinc is a key element in neuronal growth and activity and it is necessary for the normal development and functioning of the brain (Plum, Rink, \& Haase, 2010; Vallee \& Falchuk, 1993). It has been found to interact with more than 50 different types of protein that require $\mathrm{Zn}^{2+}$ to function (Vallee \& Falchuk, 1993). It can be found intracellularly in concentrations around the $100 \mathrm{pM}$ and the free $\mathrm{Zn}^{2+}$ varies in nm-pM range (Plum et al., 2010). The regulation of the physiological concentration of $\mathrm{Zn}^{2+}$ is crucial for the normal functioning of the organism (Plum et al., 2010).

Zinc deficiency produces growth retardation and immune system dysfunctions (Plum et al., 2010). Furthermore, neurologically there are several effects such as decreased nerve conduction, neuropsychiatric disorders and mental lethargy (Plum et al., 2010).Whereas a $\mathrm{Zn}^{2+}$ excess also affects the body by altering the lymphocyte function, producing gastrointestinal issues and copper deficiency (Plum et al., 2010). In the brain, $\mathrm{Zn}^{2+}$ excess causes lethargy and focal neuronal deficits (Plum et al., 2010). Recently, Permyakov et al. have shown that $\mathrm{Zn}^{2+}$ binds to the member of neuronal calcium sensor family, recoverin with a $\mathrm{K}_{\mathrm{d}}$ of $7.0 \mu \mathrm{M}$ (Permyakov, S. E. et al., 2003). Therefore, considering the role of $\mathrm{Zn}^{2+}$ in neuropathology and the high homology between recoverin and DREAM, as shown in

Figure 3.1, I suggest that DREAM may serve as a molecular target for $\mathrm{Zn}^{2+}$. To test $\mathrm{Zn}^{2+}$ interactions with DREAM I characterized DREAM emission properties in the presence of DREAM as well as circular dichroism and isothermal titration calorimetry studies. 


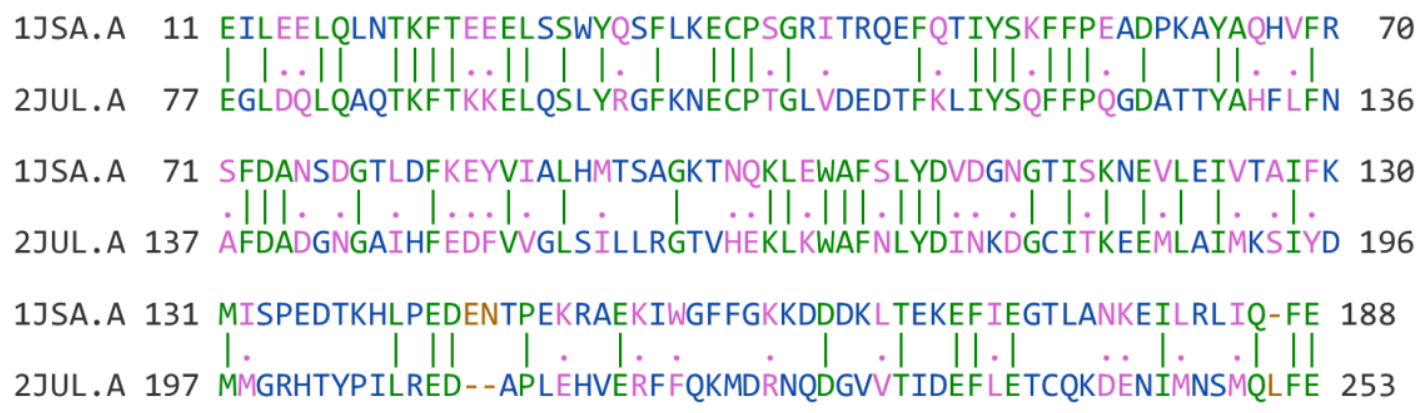

Fig. 3.1: Sequence similarity among recoverin (PDB entry 1JSA) and DREAM (PDB entry 2JUL), identical residues in green, similar residues in pink, sequence mismatch in blue and insertion/deletion in brown. Obtained from RCSB PDB Protein Comparison Tool. SmithWaterman sequence alignment (Smith \& Waterman, 1981)

\subsection{Steady state fluorescence emission}

The Trp intrinsic fluorescence emission for the DREAM WT exhibits specific transitions upon divalent metals addition along with a typical $\lambda_{\max }$ at $330 \mathrm{~nm}$. For DREAM WT, the intensity decreases upon $\mathrm{Ca}^{2+}$ and $\mathrm{Ca}^{2+} \mathrm{Mg}^{2+}$ addition, whereas for addition of $\mathrm{Mg}^{2+}$ no transition is observed with respect to the apo form. Emission spectra for Trp 169 were detected upon $\mathrm{Zn}^{2+}$ addition to DREAM in the presence and absence of divalent metals, to monitor $\mathrm{Zn}^{2+}$ binding to DREAM and its impact on Trp 169 surrounding. For the apo, $\mathrm{Ca}^{2+}$ , $\mathrm{Mg}^{2+}$ and $\mathrm{Ca}^{2+} \mathrm{Mg}^{2+}$ bound forms the $\mathrm{Zn}^{2+}$ addition resulted in an increase in the emission at $330 \mathrm{~nm}$, suggesting $\mathrm{Zn}^{2+}$ binds to the protein and triggers changes in the Trp environment. 


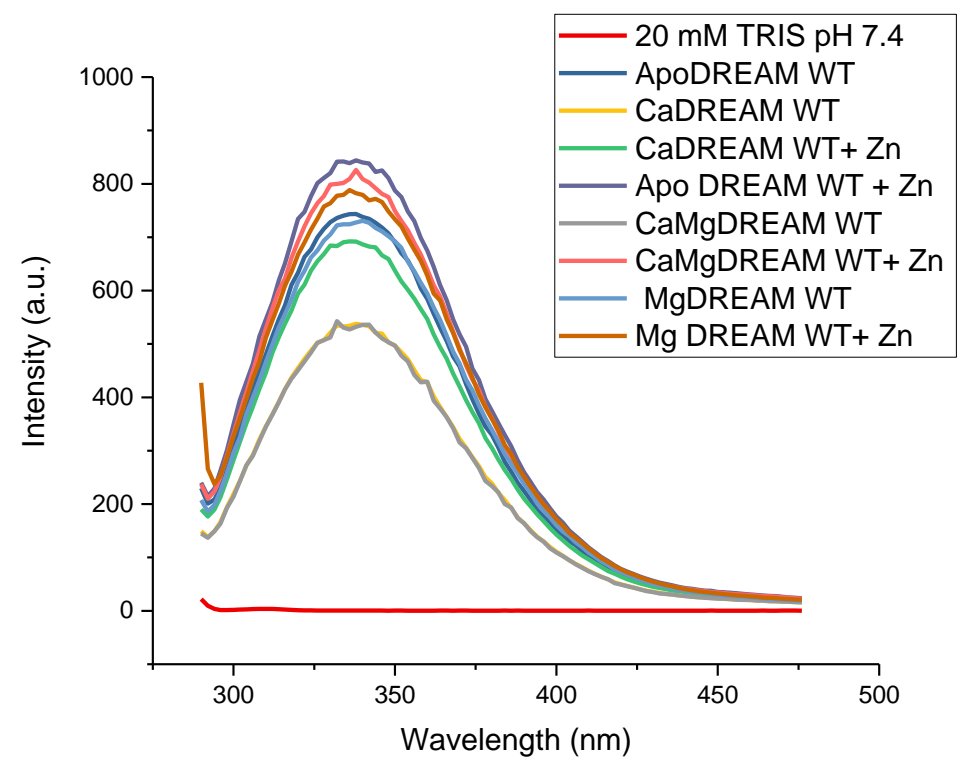

Fig. 3.2: Steady-state fluorescence emission of Trp for DREAM-WT upon $500 \mu \mathrm{M} \mathrm{Zn^{2+ }}$ addition in the presence and absence of $\mathrm{Ca}^{2+}$ and/or $\mathrm{Mg}^{2+}$.

Furthermore, titration curves for $\mathrm{Zn}^{2+}$ binding to DREAM WT were obtained by adding increasing concentration of $\mathrm{Zn}^{2+}$ to DREAM samples and the Trp emission intensity was monitored in the presence and absence of $\mathrm{Ca}^{2+}$ shown in Fig.ure 3.3.
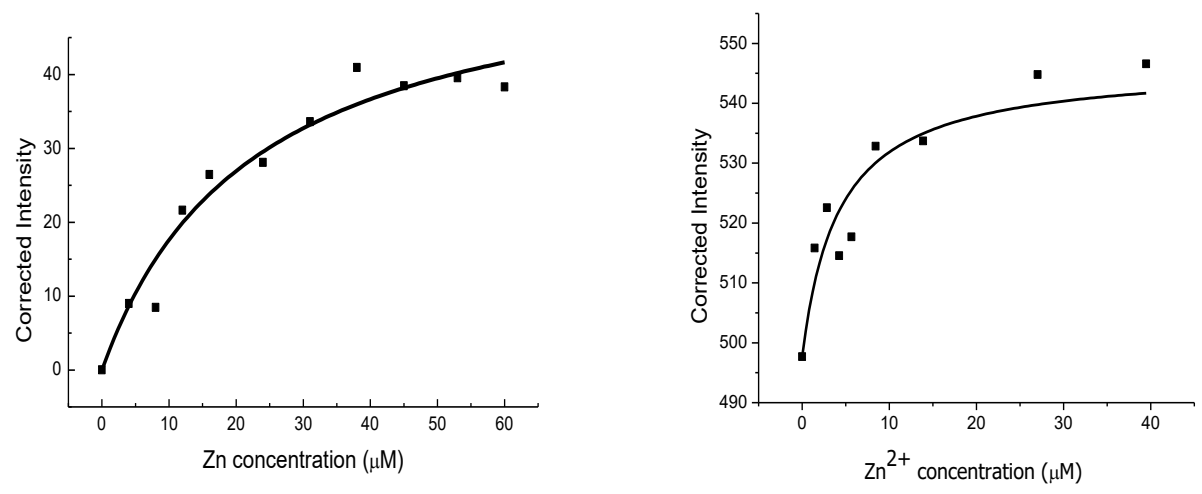

Fig. 3.3: Trp fluorescence emission for the $\mathrm{Zn}^{2+}$ association to $\mathrm{Ca}^{2+}$ (right) and apo (left) DREAM WT 
The equilibrium dissociation constants were determined and are shown in Table 3.1. Dissociation constant for $\mathrm{Zn} 2+$ binding to the apo form of the protein is around 3 times lower than the one for the $\mathrm{Ca}^{2+}$ bound form, suggesting a stronger affinity of $\mathrm{Zn}^{2+}$ for DREAM WT in the absence of $\mathrm{Ca}^{2+}$.

\begin{tabular}{|c|c|}
\hline & $\mathrm{K}_{\mathrm{d}}(\mu \mathrm{M})$ \\
\hline Apo DREAMWT & $4.3 \pm 0.9$ \\
\hline $\mathrm{Ca}^{2+}$ DREAMWT & $14.0 \pm 3.1$ \\
\hline
\end{tabular}

Table 3.1: Dissociation constant for $\mathrm{Zn}^{2+}$ association to DREAMWT in the presence and absence of $\mathrm{Ca}^{2+}$.

\subsection{CD measurements}

The secondary structure changes upon $\mathrm{Zn}^{2+}$ addition to the protein were measured using circular dichroism for DREAM WT in the absence and presence of divalent metals shown in Fig.ure 3.6

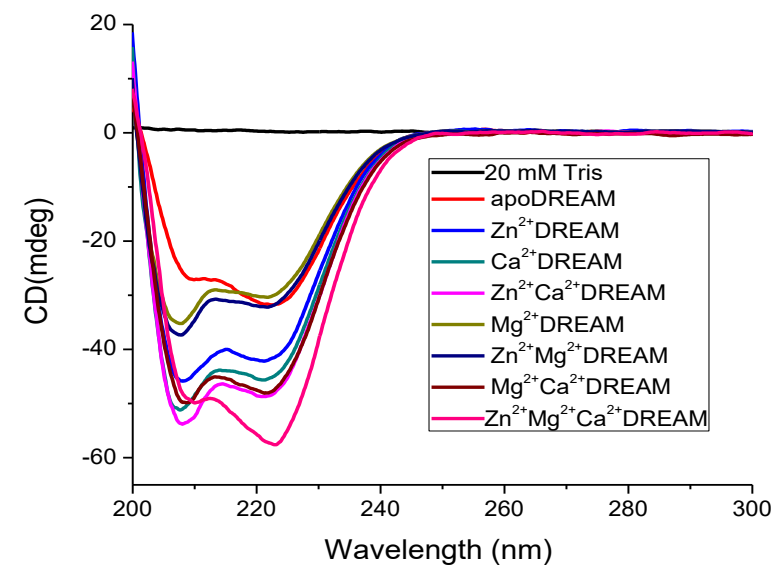

Fig. 3.4: Secondary structure characterization of DREAM WT upon $\mathrm{Zn}{ }^{2+}$ addition in the absence and presence of $\mathrm{Ca}^{2+}, \mathrm{Mg}^{2+}$ and $\mathrm{Ca}^{2+} \mathrm{Mg}^{2+}$. 
A decrease in $\mathrm{CD}$ signal was observe upon $\mathrm{Zn}^{2+}$ in all the cases, for the apo form a more pronounced decrease in the CD signal was observed when compared to the $\mathrm{Ca}^{2+}, \mathrm{Mg}^{2+}$ and $\mathrm{Ca}^{2+} \mathrm{Mg}^{2+}$ forms. Suggesting the $\mathrm{Zn}^{2+}$ binding to apo DREAM leads to the significant increase in the protein secondary structure and possibly to the stabilization of the protein structure. In decrease in the $\mathrm{CD}$ signal in the presence of $\mathrm{Mg}^{2+}$ and $\mathrm{Ca} 2+$ was less pronounced, suggesting that the presence of $\mathrm{Mg}^{2+}$ and $\mathrm{Ca}^{2+}$ in the EF-hands modulates $\mathrm{Zn} 2+$ impact on the protein secondary structure.

3.4 Impact of $\mathrm{Zn}^{2+}$ on DREAM interactions with hydrophobic probe, 1,8-ANS

The fluorescence emission of 1,8 ANS-DREAM complex in the presence and/or absence of $\mathrm{Ca}^{2+}, \mathrm{Mg}^{2+}$ was monitored in order to determine impact of $\mathrm{Zn} 2+$ binding on the accessibility of hydrophobic surfaces on the protein surface. The emission spectra for DREAM in the absence/ presence of divalent ions are shown in Figure 3.4 .

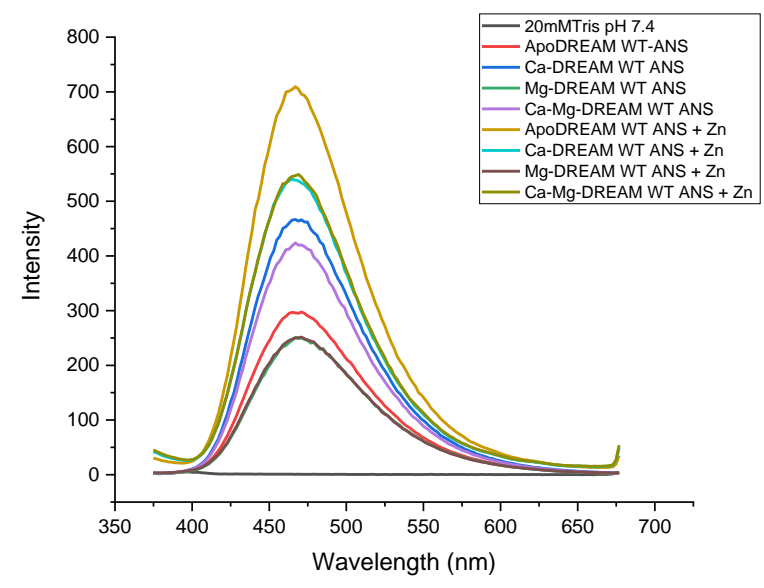

Fig. 3.5: Emission spectra of 1,8 ANS-DREAM WT complex in the presence and/or absence of $\mathrm{Ca}^{2+}, \mathrm{Mg}^{2+}$ and $\mathrm{Zn}^{2+}$. 
For the 1,8 ANS-DREAMWT apo, $\mathrm{Ca}^{2+}$, and $\mathrm{Ca}^{2+} \mathrm{Mg}^{2+}$ bound forms the $\mathrm{Zn}^{2+}$ addition resulted in an increase in the 1,8-ANS emission intensity. The largest increase in intensity was observed for the apo form and interestingly for the $\mathrm{Mg}^{2+}$ bound form of DREAM W, the $\mathrm{Zn}^{2+}$ triggered changes in the emission intensity were negligible that is consistent with the CD data. Furthermore, the equilibrium dissociation constant for 1,8 ANS binding to DREAM in the presence of $\mathrm{Zn}^{2+}$ was determined by monitoring the increase in the emission intensity upon $\mathrm{Zn}^{2+}$ titration into 1,8 ANS-DREAMWT complex in the presence and absence of $\mathrm{Ca}^{2+}$. The corresponding titration curves areas shown in Figure 3.6.
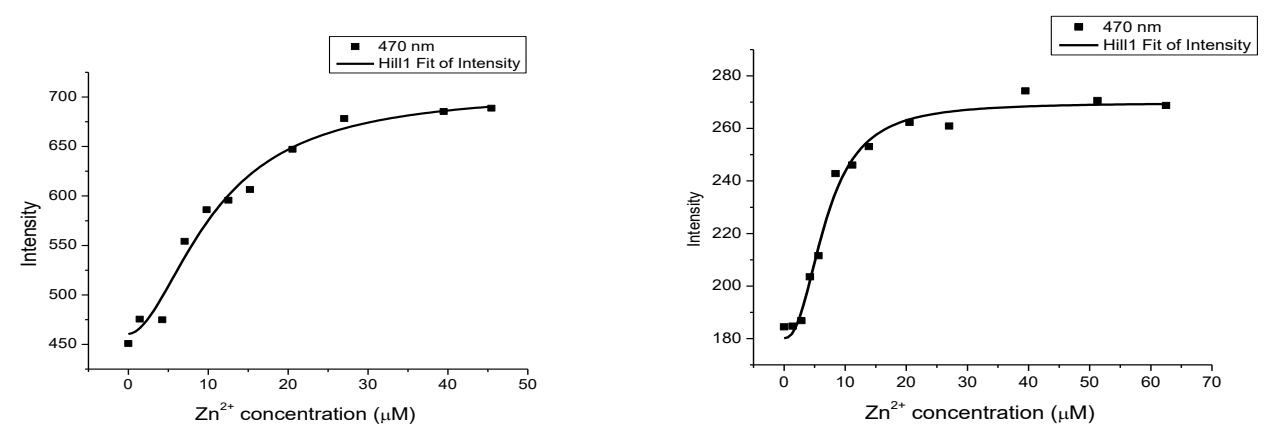

Fig. 3.6: $\mathrm{Zn}^{2+}$ association to $\mathrm{Ca}^{2+}$ and Apo DREAM WT in the presence of 1,8 ANS

The Kd values were obtained by fitting the data using the Hill equation (Eq. 4.1) and are shown in Table 3.2. Slightly smaller $\mathrm{K}_{\mathrm{d}}$ value was determined for apoDREAM compared to the $\mathrm{Ca}^{2+}$ bound protein, in agreement with the Trp emission data.

\begin{tabular}{|c|c|}
\hline & $\mathrm{K}_{\mathrm{d}}(\mu \mathrm{M})$ \\
\hline Apo DREAMWT & $6.9 \pm 0.6$ \\
\hline $\mathrm{Ca}^{2+}$ DREAMWT & $10.76 \pm 1.46$ \\
\hline
\end{tabular}

Table 3.2: Dissociation constant for 1,8 ANS - DREAMWT association with $\mathrm{Zn}^{2+}$ in the presence and absence of $\mathrm{Ca}^{2+}$. 
In addition, the impact of $\mathrm{Zn}^{2+}$ on the fluorescence lifetimes of 1,8-ANS: DREAM complex in the presence and absence of $\mathrm{Ca}^{2+}$ was probed using frequency modulation approach and the date are presented in Fig. 3.7. The lifetime values were obtained from a fit of experimental data using a three exponential decay model and the fitting parameters are summarized in Table 3.3. The lifetime for unbound 1,8-ANS was fixed to $0.27 \mathrm{~ns}$ (Gonzalez \& Miksovska, 2014). Upon $\mathrm{Zn}^{2+}$ addition, $\tau_{1}$ decreased from 5.9 ns to approximately $3.0 \mathrm{~ns}$ for both apo and $\mathrm{Ca}^{2+}$ bound protein, while $\mathrm{Zn}^{2+}$ association does not impact the longer lifetime, $\tau_{2}$. These results suggest that the 1,8-ANS-binding site with the shorter lifetime, $\tau_{1}$, is more sensitive to the structural changes triggered $\mathrm{Zn}^{2+}$ binding whereas the emission properties of 1,8 -ANS bound to the second site are only slightly affected by the $\mathrm{Zn}^{2+}$ association.
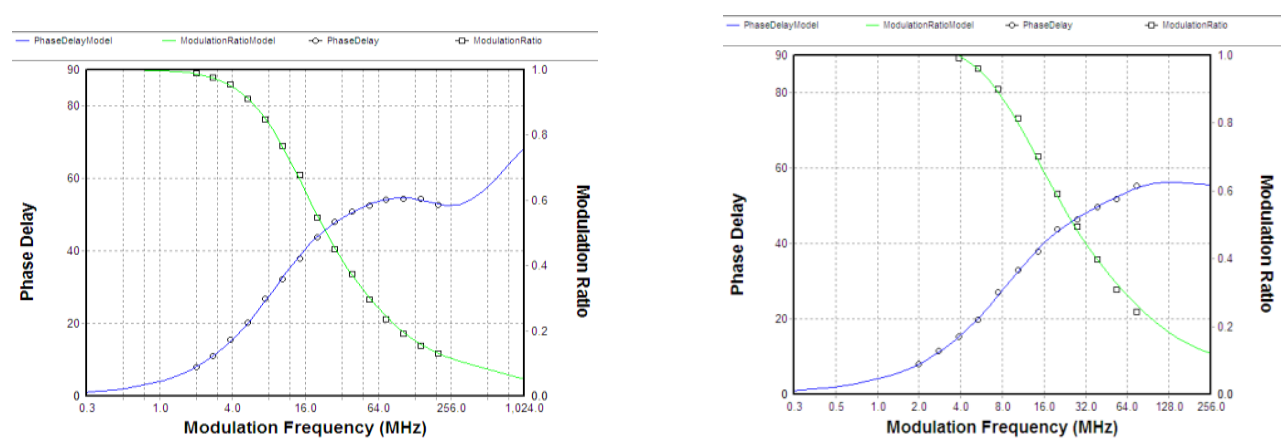

Fig. 3.7: Frequency domain intensity decay for $\mathrm{Zn}^{2+}$ addition to $\mathrm{Ca}^{2+}$ bound 1,8 -ANSDREAMWT (left) and 1,8 ANS- apo DREAM-WT (right). The solid lines correspond to the fit of the experimental data using a sum of three exponential decay model. 
Table 3.3: 1,8 ANS lifetime for apo and Ca-DREAM WT in the presence of $\mathrm{Zn}^{2+}$ fitted to three exponential decays with a fixed lifetime for 1,8 ANS of 0.27 ns. The lifetime values for 1,8 ANS bound to DREAM in the absence of $\mathrm{Zn}^{2+}$ were previously determined by Gonzalez (Gonzalez \& Miksovska, 2014)

\begin{tabular}{|c|c|c|c|c|c|}
\hline & $\tau_{1}(\mathrm{~ns})$ & $\tau_{2}(\mathrm{~ns})$ & $\alpha_{1}$ & $\alpha_{2}$ & $\chi^{2}$ \\
\hline 1,8 ANS Apo DREAM WT & $5.9 \pm 0.1$ & $16.2 \pm 0.7$ & 0.13 & 0.23 & 1.16 \\
\hline $1,8 \mathrm{ANS} \mathrm{Ca}^{2+}$ DREAM WT & $5.9 \pm 0.2$ & $17.6 \pm 0.5$ & 0.18 & 0.42 & 1.13 \\
\hline 1,8 ANS-Apo DREAMWT $+\mathrm{Zn}^{2+}$ & $2.89 \pm 0.2$ & $14.4 \pm 0.2$ & 0.07 & 0.06 & 9.45 \\
\hline 1,8 ANS-Ca $^{2+}$ DREAMWT $+\mathrm{Zn}^{2+}$ & $3.13 \pm 0.09$ & $14.1 \pm 0.1$ & 0.05 & 0.05 & 4.05 \\
\hline
\end{tabular}

\subsection{ITC studies}

Isothermal calorimetry studies were performed to determine the dissociation constant and thermodynamic parameters for $\mathrm{Zn}^{2+}$ binding to apo DREAM. The binding isotherm is shown in Fig. 3.8. The data were analyzed using one binding site model. The $\mathrm{Zn}^{2+}$ binding to the protein is exothermic, with the reaction enthalpy change of $-5.1 \mathrm{kcal} \mathrm{mol}^{-1}$ (Table 3.4 ) and the equilibrium dissociation constant was determined to be $3 \pm 1 \mu \mathrm{M}$. This value of $3 \pm 1 \mu \mathrm{M}$ is similar to the $\mathrm{K}_{\mathrm{d}}$ value obtained from monitoring changes in $\operatorname{Trp} 169$ emission in apo DREAM, $\mathrm{K}_{\mathrm{d}}=4.3 \pm 0.9 \mu \mathrm{M}$ and 1,8-ANS:apoDREAM emission, $\mathrm{K}_{\mathrm{d}}=6.9 \pm 0.6$ $\mu \mathrm{M}$. 


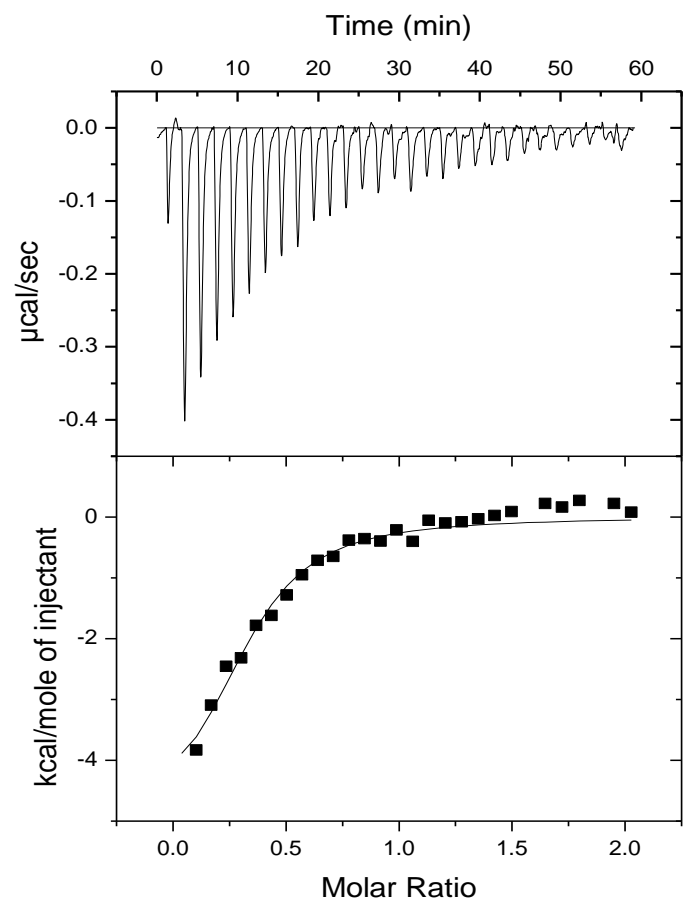

Fig. 3.8: ITC Isotherms for $\mathrm{Zn}^{2+}$ association to DREAM in the absence of $\mathrm{Ca}^{2+}$, the upper panel refers to thermal power as function of time, and the lower panel represent the integrated reaction heat $\Delta \mathrm{H}$ in $\mathrm{kcal} / \mathrm{mol}$.

\begin{tabular}{|l|c|c|c|}
\hline & $\mathrm{K}_{\mathrm{D}}(\mu \mathrm{M})$ & $\Delta \mathrm{H}(\mathrm{kcal} / \mathrm{mol})$ & $\mathrm{T} \Delta \mathrm{S}(\mathrm{kcal} / \mathrm{mol})$ \\
\hline $\mathrm{Zn}^{2+}$ apo DREAM WT & $2.6 \pm 1.0$ & -5.1 & 23.7 \\
\hline
\end{tabular}

Table 3.4: Equilibrium Dissociation constant of $\mathrm{Zn}^{2+}$ binding to DREAM in the absence of $\mathrm{Ca}^{2+}$ Using one model sequential binding fitting. 


\subsection{Discussion}

The fluorescence and $\mathrm{CD}$ results presented in the chapter for $\mathrm{Zn}^{2+}$ interactions with DREAM suggest that $\mathrm{Zn}^{2+}$ binds to DREAM with relatively high affinity, $\mathrm{K}_{\mathrm{d}} \sim 5 \mu \mathrm{M}$. The increase in the emission spectra for the Trp residue indicates that $\mathrm{Zn}^{2+}$ association impact the tertiary structure of the protein. The dissociation constant obtained for $\mathrm{Zn}^{2+}$ binding to apo and $\mathrm{Ca}^{2+}$ DREAM of $5 \mu \mathrm{M}$ and $14 \mu \mathrm{M}$, respectively, is similar to the value reported for recoverin, $\mathrm{Kd}=7 \mu \mathrm{M}$ (Permyakov, S. E. et al., 2003). The dissociation constant obtained for $\mathrm{Zn}^{2+}$ binding to DREAM in the absence of $\mathrm{Ca}^{2+}$ through fluoresce emission of $4 \mu \mathrm{M}$, is very close to the $\mathrm{K}_{\mathrm{d}}=3 \mu \mathrm{M}$ obtained through isothermal calorimetry measurements, suggesting a higher affinity of $\mathrm{Zn}{ }^{2+}$ to DREAM in the absence of the physiological ligand. In addition, the decrease in the CD signal suggest a stabilizing effect on the protein structure similar to the one occurring upon $\mathrm{Ca}^{2+}$ addition. Furthermore, the addition of $\mathrm{Zn}^{2+}$ to $1,8 \mathrm{ANS}$-DREAM complex resulted in an increase in the fluorescence intensity, suggesting a higher exposure of the hydrophobic surfaces due to the $\mathrm{Zn}^{2+}$ binding. The emission data is in agreement with the 1,8 ANS lifetime values, which demonstrate a lower $\tau_{1}$ upon $\mathrm{Zn}^{2+}$ addition, suggesting that 1,8 ANS binding site 1 is more sensitive to the $\mathrm{Zn}^{2+}$ conformational changes. Overall, the data obtained confirm that $\mathrm{Zn}^{2+}$ binds to DREAM in apo and $\mathrm{Ca}^{2+}$ bound form, and association of $\mathrm{Zn}+$ to the protein triggers changes in protein. Maret et al studied zinc-protein interactions and reported that $\mathrm{Zn}^{2+}$ is usually coordinated in proteins by four ligands with the side chain of Cys, His, Glu, or Asp being the most common ligands (Maret \& Li, 2009). The inspection of the monomeric 
structure of the calcium bound protein (PDB entry 2JUL, Lusin et al, 2008) did not reveal a possible binding site on the DREAM monomer. However, it is likely that the $\mathrm{Zn}^{2+}$ association to the protein requires the presence of the apo protein tetramer or $\mathrm{Ca}^{2+}$ bound protein dimer and thus additional studies are necessary to identify residues that participate in $\mathrm{Zn}^{2+}$ coordination. 


\section{MOLECULAR MECHANISM OF DREAM DIMERIZATION}

\subsection{Introduction}

Unlike traditional EF hand sensors, such as calmodulin and troponin $\mathrm{C}$ that remind in the monomeric form in the absence and presence of $\mathrm{Ca}^{2+}, \mathrm{Ca}^{2+}$ association to other CBPs triggeres a structural transition that facilittes protein oligomeriztion. For example, proteins belonging to S100 calcium binding protein subfamily are known to undergo dimerization upon $\mathrm{Ca}^{2+}$ binding to the EF hands. Some members of the neuronal calcium sensor family also undergo $\mathrm{Ca}^{2+}$ triggered dimerization such as recoverin, GCAP 1-5 and VILIP1(Ames, 2018) (James 2018[JM3]). The available structures of dimeric form of individual proteins suggest, that each protein adopt a unique dimeric structure, as shown in Fig.ure 4.1, likely due to a distinc physiological role of each proteins (James, 2018). For example, the dimeric structure of $\mathrm{Ca}^{2+}$ bound VILIP-1 shows that the binding interface is formed through contacts beween $\alpha$-helices located in EF-hand 4 of the $\mathrm{C}$ - terminal domain ( $\mathrm{Li}$, Pan, Braunewell, \& Ames, 2011) (Li et al., 2011[JM4]), whereas in recoverin, the exiting $\alpha$-helix from the EF-hand 4 interacts with hydrophobic residues in a cavity located between EF-hand 1 and EF-hand 2 (Myers et al., 2013) (Myers et al., 2013[JM5]) 


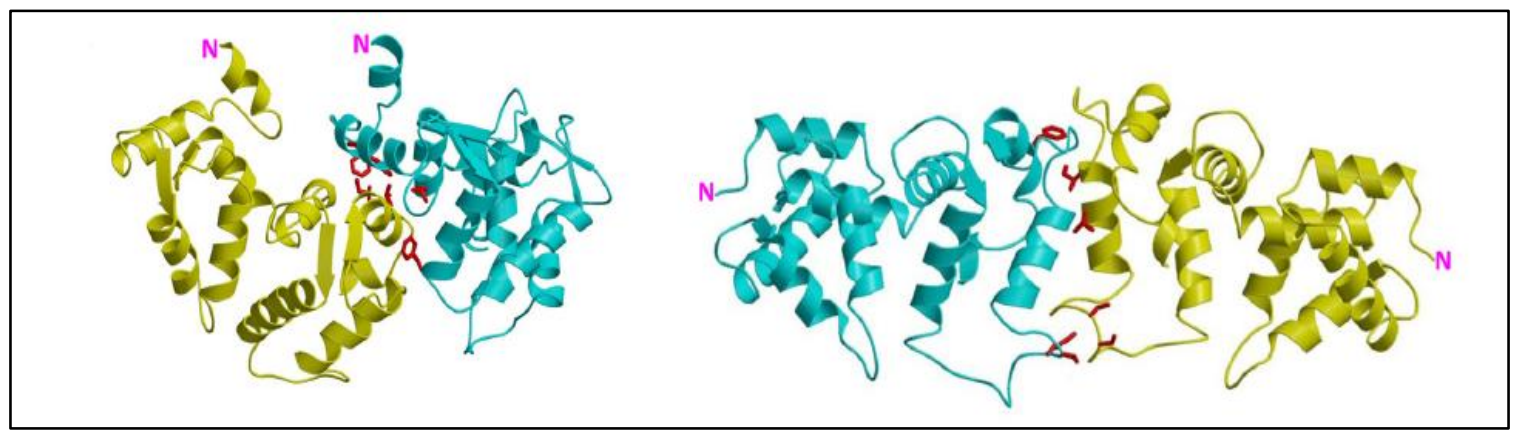

Fig. 4.1: The structure of the dimeric form of recovering (left) and VILIP-1 (right) in $\mathrm{Ca}^{2+}$ bound form. Individual monomers are colored in yellow and blue and side chains of residues in the binding interfaces are shown in red. Adapted from Ames 2018 (Ames, 2018)

Based on the NMR structure of $\mathrm{Ca}^{2+}$ bound DREAM monomer, Lusin et al. suggested that DREAM forms a dimeric structure with the head to tail orientation of the $\mathrm{C}$ - and $\mathrm{N}$ terminal domain (Lusin et al, 2018). The dimeric form was proposed to be stabilized by hydrohobic interactions between Leu residues in the N-terminal domain (Leu 155 and Leu 159) of one monomer and Leu 251 in the C-terminal domain of the second monomer. Albeit replacement of Leu residues by Ala did not abolished the formation of the dimers, but the equilibrium constant for the protein dimerization decreased (Lusin et al, 2018). The DREAM dimeric structure is destabilized at an increased concentration on sodium chloride as observed in the homo Förster resonance energy transfer measurement , suggesting that ionic interactions also contribute to the formation of DREAM dimeric form (unpublished results from Dr. Miksovska group).

In order to better understand the mechanism of $\mathrm{Ca}^{2+}$ triggered protein dimerization and the mechanism of signal transduction in DREAM, we prepared a DREAM construct with the aim to abolish protein dimerization. Based on the previously published model structure of DREAM (Lusin et al, 2018), a protein docking and molecular dynamic simulation of the 
DREAM dimer structure, Fig. 4.3, (Miksovska laboratory, unpublished results) and the fact that other member of neuronal calcium sensor family, NCS1, does not form a dimer[JM6] (Pandalaneni et al., 2015), I proposed to construct a chimeric variant of a protein with Leu residues in position 155 and 158 replaced by residues Thr and Leu, that are found in NCS1 respectively. In addition, since the simulated structure of DREAM dimer shows an interactions between Arg residues(Arg 200 and Arg 208) in the long loop conecting EFhand 3 and EF-hand 4, the residues in the loop were replaced by residues found in the loop in NCS-1. I label this chimeric form of the protein DREAM-NCS-1. The alignment of the sequence of DREAM-NCS-1 and the sequence of DREAM WT in Fig. 4.2. The properties of DREAM-NCS-1 variant were characterized using fluorescence and CD spectroscopy and the interactions with the peptides mimicking the DREAM binding sites in T1 domain of potassium voltage channels were determined.

MELELSTVRHOPEGLDQLQAOTKETKKELQSLYRGEKNECPTGLVDEDTEKLIYSQFEPQGDATTYAHELFNAFDAD MELELSTVRHQPEGLDQLQAQTKETKKELQSLYRGEKNECPTGLVDEDTEKLIYSOFFPQGDATTYAHFLFNAFDAD

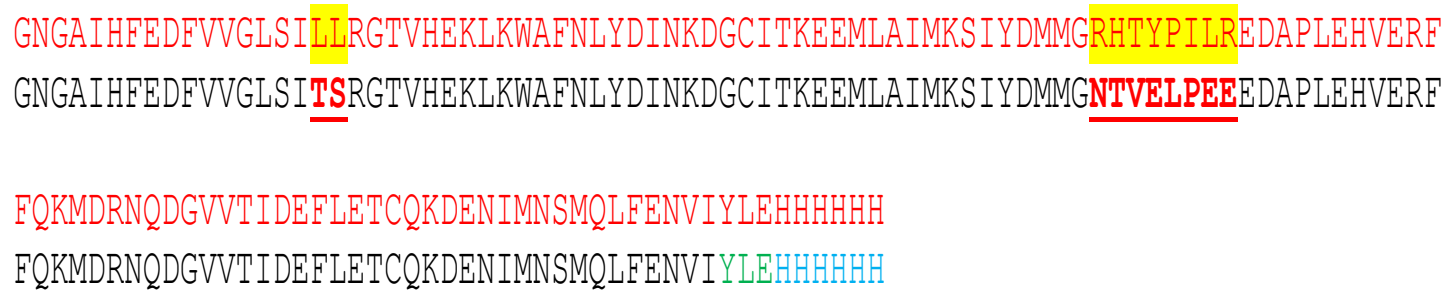

Fig. 4.2: Sequence of mouse DREAM WT (red) with a start methionine residue (green) and a C-terminus His-tag (blue) connected by tripeptide linker (green). The DREAMNCS (black) has identical sequence to the DREAM WT except residues L158, Leu159 replaced by Thr and Ser and the loop between EF-hand 3 and 4 (shown in yellow ) replaced by the amino acid sequence found in human NCS-1 (shown in bold red). 

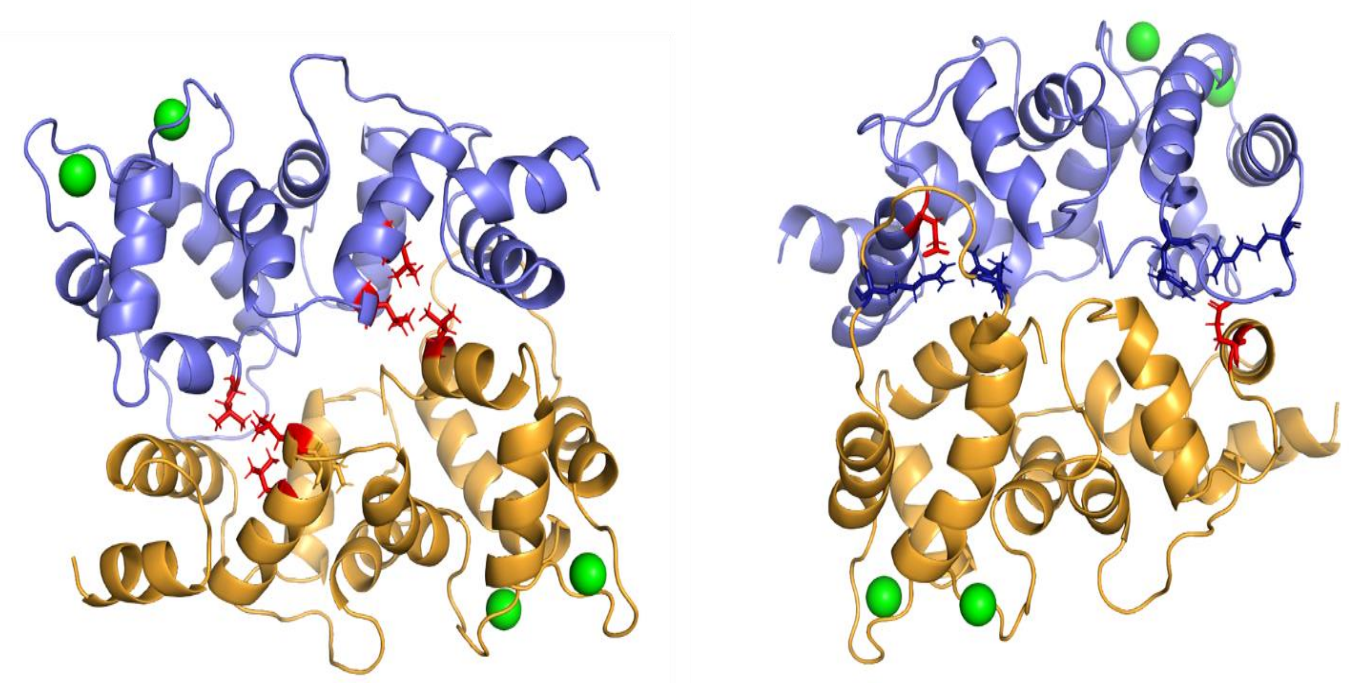

Fig. 4.3: Model structure of DREAM dimer based on the NMR structure of DREAM monomer (PDB entry 2JUL). Left panel shows hydrophobic interactions between Leu 155, 159 and 251 and right panel show a salt bridge between Arg 200, Arg 207 (in blue) and Glu 103 (in red).

\subsection{Steady state fluorescence emission}

Trp 169 fluorescence emission spectrum of DREAM WT presents a characteristic $\lambda_{\max }$ at $330 \mathrm{~nm}$, Fig. 4.4. The emission intensity decreases upon $\mathrm{Ca}^{2+}$ and $\mathrm{Ca}^{2+} \mathrm{Mg}^{2+}$ addition to the apo protein sample, whereas upon addition of $\mathrm{Mg}^{2+}$, no changes are observed with respect to apoDREAM WT. Interestingly, when analyzing the Trp steady state emission of the DREAM-NCS1 variant, the spectrum of the apoform exhibits a red shift with respect to DREAM WT, with a $\lambda_{\max }$ at $337 \mathrm{~nm}$. Furthermore, , the emission intensity increases upon $\mathrm{Ca}^{2+}$ and $\mathrm{Ca}^{2+} \mathrm{Mg}^{2+}$ addition, while $\mathrm{Mg}^{2+}$ binding to the apoprotein does not modulate the emission intensity as shown in Fig. 4.4. The increase in the Trp 169 emission observed for $\mathrm{Ca}^{2+}$ DREAM-NCS-1 is distinct from the DREAM WT, which exhibits an opposite trend, decrease in the emission internist in the presence of $\mathrm{Ca}^{2+}$. 

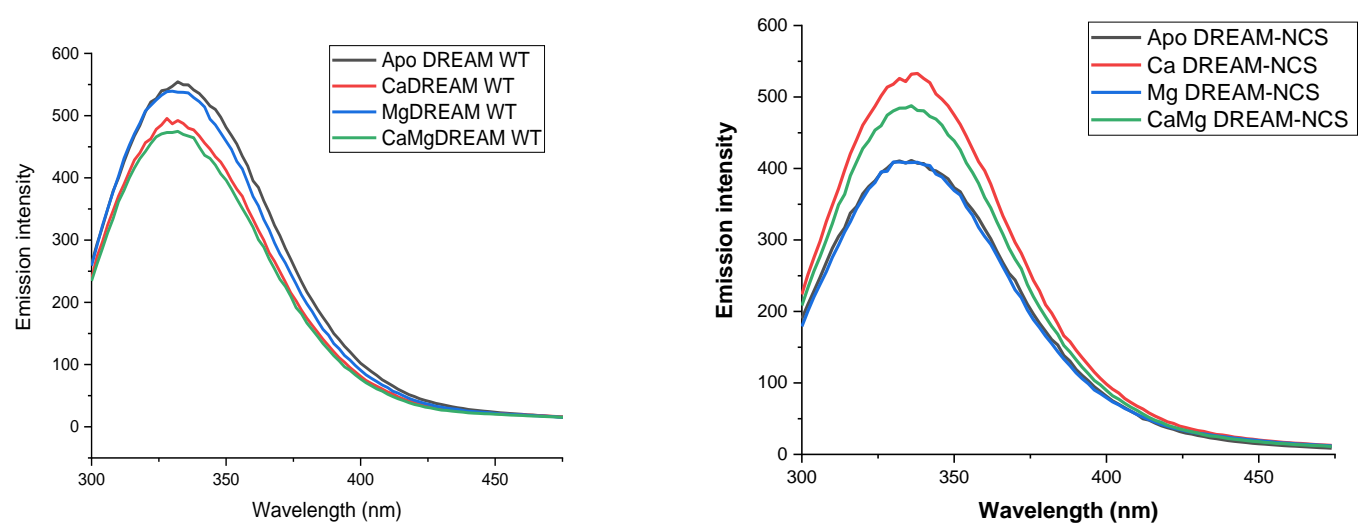

Fig. 4.4: Steady-state fluorescence emission of Trp for DREAM-WT (left) and DREAM-NCS1 (right) in the presence and absence of $\mathrm{Ca}^{2+}$ and/or $\mathrm{Mg}^{2+}$.

\subsection{CD spectra}

The changes in the secondary structure were monitored by performing CD measurements for both DREAM WT and DREAM-NCS 1 in the presence and absence of divalent metals. For DREAM WT and DREAM-NCS 1 a decrease in the CD signal is observed upon addition of divalent metals, similar to other NCS where $\mathrm{Ca}^{2+}$ binding leads to the increase in the $\alpha$-helical contain of the protein Azam at al, 2019 (Azam \& Miksovska, 2019)[JM7]. These results together with the emission data indicate that $\mathrm{Ca}^{2+}$ binds to the chimeric version of the protein. In addition, the substitution of Leu residues and the modification of the loop connecting the EF-hand 3 and EF-hand 4 does not destabilizes the protein secondary structure and protein fold. 

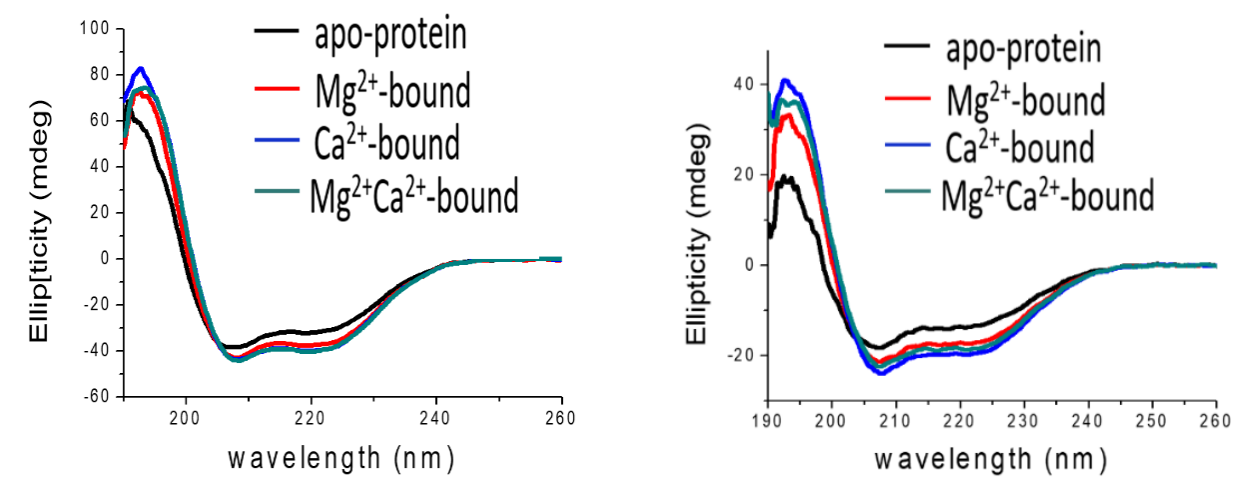

Fig. 4.5: Circular dichroism spectra for DREAM WT (left), and DREAM-NCS1 (right) in the presence and absence of $\mathrm{Ca}^{2+}$ and/or $\mathrm{Mg}^{2+}$.

4.4 $\mathrm{Ca}^{2+}$ triggered exposure of hydrophobic cavities

1,8 -ANS is a small hydrophobic molecule that is very weakly fluorescent in aqueous solution but its fluorescent quantum yield increases significantly upon binding to hydrophobic cavities on a protein surface (Gasymov \& Glasgow, 2007). Two binding sites with a high affinity for 1,8-ANS were identified for DREAM WT in the C-terminal domain and the analysis of the emission data indicates that 1,8-ANS binds to DREAM WT in $\mathrm{Ca}^{2+}$ dependent manner. (Gonzalez \& Miksovska, 2014) The emission spectra of 1,8ANS bound to DREAM-NCS 1 in the apo form and in the presence of $\mathrm{Ca}^{2+}$ and/or $\mathrm{Mg}^{2+}$ are shown in Fig. 4.6. The results show a transition towards increase emission intensity of 1,8-ANS upon binding of $\mathrm{Ca}^{2+}$ as well as in the presence of $\mathrm{Mg}^{2+}$. The $\lambda_{\max }$ for apo DREAM is around the $471 \mathrm{~nm}$, while the metal bound protein exhibits a red to a $\lambda$ max of $491 \mathrm{~nm}$ shift with respect to apo DREAM. 


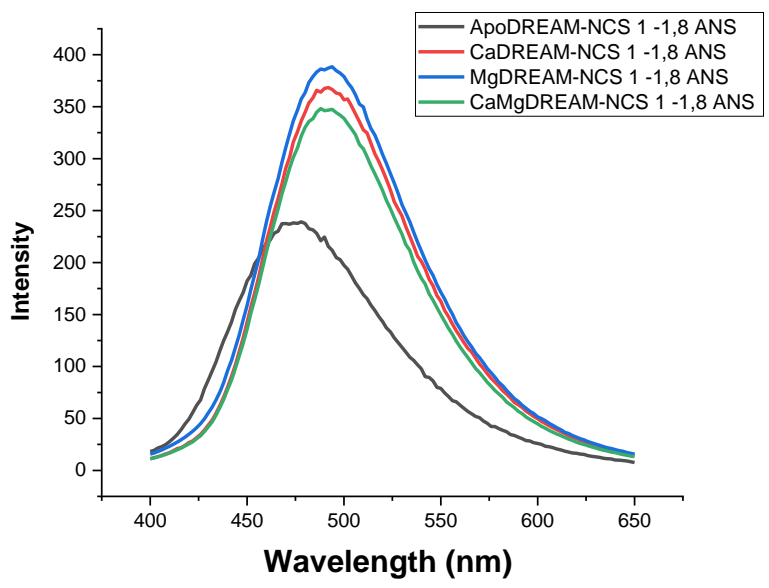

Fig. 4.6: 1,8 ANS-DREAM-NCS 1 emission spectra upon $\mathrm{Ca}^{2+}, \mathrm{Mg}^{2+}$ and $\mathrm{Ca}^{2+} \mathrm{Mg}^{2+}$ addition.

In order to gain more information about 1,8-ANS interactions with DREAM-NCS-1, the equilibrium dissociation constant for 1,8- ANS binding to DREAM were determined by titrating apo DREAM-NCS 1 and $\mathrm{Ca}^{2+}$ DREAM-NCS-1 with 1,8-ANS. The titration curves were constructed by plotting the increase in the emission intensity for 1,8-ANS additions to DREAM-NCS-1 as shown in Fig. 4.7.
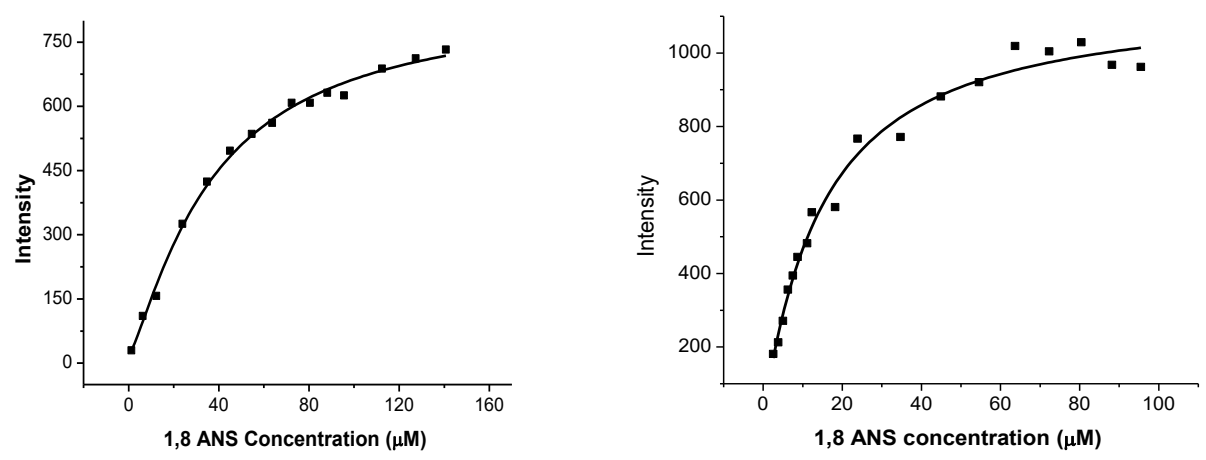

Fig. 4.7: Titration curves for 1,8-ANS binding to apoDREAM-NCS 1 (left) and $\mathrm{Ca}^{2+}$ DREAM-NCS 1 (right). 
Affinity constants for 1,8 -ANS binding to apoDREAM-NCS-1 and $\mathrm{Ca}^{2+}$ bound DREAM were determined by analyzing the titration curves using Hill equation (Eq. 4.1):

$$
F=B_{\max } \frac{[1,8-A N S]^{n}}{[1,8-A N S]^{n}+K_{D}}
$$

where $\mathrm{F}$ is the observed emission intensity, $\mathrm{n}$ is the Hill coefficient, $\mathrm{K}_{\mathrm{D}}$ is the equilibrium dissociation constant and $\mathrm{B}_{\max }$ is the proportionality constant. The fitting parameters are summarized in Table 4.1 together with the data obtained for 1,8-ANS binding to DREAM WT. Interestingly, the affinity of 1,8-ANS for DREAM-NCS-1 increased in the apo form and $\mathrm{Ca}^{2+}$ bound form, compared to the DREAM WT, pointing towards increased accessibility of the hydrophobic sites in the chimeric variant.

Table 4.1: Dissociation constants and Hill coefficients for 1,8 ANS binding to DREAM-NCS1 and DREAM WT.

\begin{tabular}{|c|c|c|}
\hline & $\mathrm{K}_{\mathrm{D}}(\mu \mathrm{M})$ & $\mathrm{n}$ \\
\hline Apo DREAM-WT & $195 \pm 20$ & $1.1 \pm 0.1$ \\
\hline Apo DREAM-NCS 1 & $32 \pm 2$ & $1.9 \pm 0.1$ \\
\hline $\mathrm{Ca}^{2+}$ DREAM-WT & $62 \pm 4$ & $1.1 \pm 0.1$ \\
\hline $\mathrm{Ca}^{2+}$ DREAM-NCS 1 & $22 \pm 4$ & $1.3 \pm 0.2$ \\
\hline
\end{tabular}




\subsection{Fluorescence lifetime of Trp169}

Lifetime decay parameters for the Trp 169 residue were determined using a frequency domain approach and the plot of the phase shift and modulation ratio as a function of
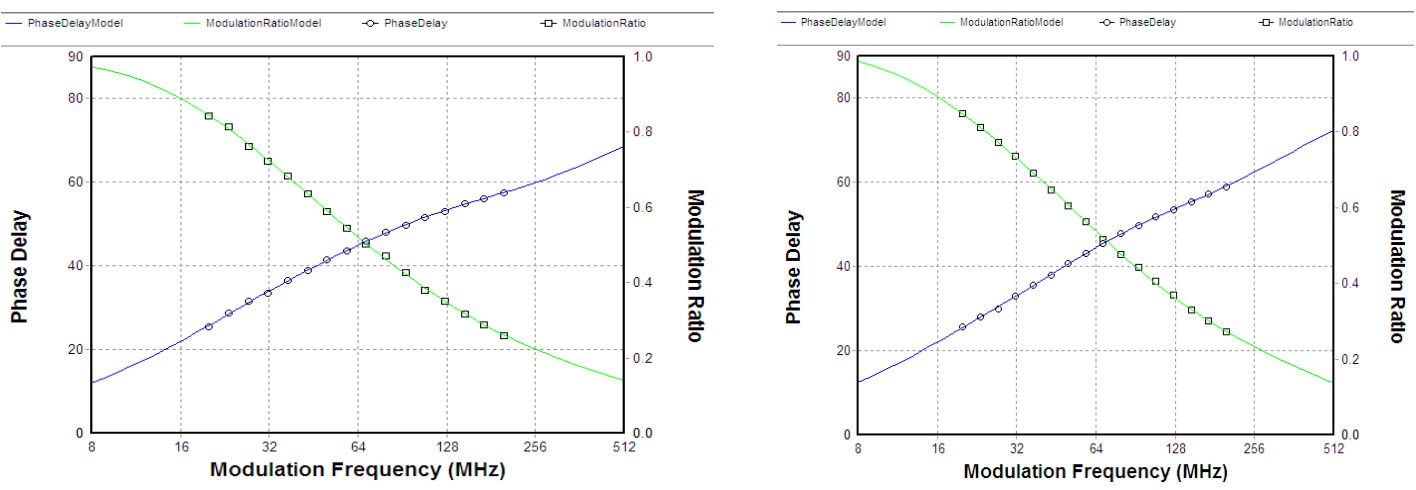

Fig. 4.8: Frequency domain Trp intensity decay for apo DREAM-NCS 1(left) and $\mathrm{Ca}^{2+}$ bound DREAM-NCs 1 (right). The solid lines correspond to the fit of the experimental data using a sum of three exponential decay model

modulation frequency is shown in Fig. 4.8. The curves were analyzed using sum of three exponential decay model and the decay parameters are summarized in Table 4.2 for

Table 4.2: : Emission decay parameters for DREAM WT and DREAM-NCS 1 in the presence and absence of $\mathrm{Ca}^{2+}$ and $\mathrm{Mg}^{2+}$.

\begin{tabular}{|c|c|c|c|c|c|c|c|c|}
\hline & $\begin{array}{c}\text { Average } \\
\text { lifetime } \\
\text { (ns) }\end{array}$ & $\tau_{1}(\mathrm{~ns})$ & $\tau_{2}(\mathrm{~ns})$ & $\tau_{3}(\mathrm{~ns})$ & $\alpha_{1}$ & $\alpha_{2}$ & $\alpha_{3}$ & $\chi^{2}$ \\
\hline Apo DREAM WT & 3.69 & $\begin{array}{c}0.39 \pm \\
0.03\end{array}$ & $\begin{array}{c}2.28 \pm \\
0.1\end{array}$ & $6.6 \pm 0.3$ & $\begin{array}{c}0.2 \\
9\end{array}$ & $\begin{array}{c}0.2 \\
9\end{array}$ & $\begin{array}{c}0.2 \\
9\end{array}$ & 4.38 \\
\hline $\mathrm{Ca}^{2+}$ DREAM WT & 4.07 & $\begin{array}{c}0.47 \pm \\
0.02\end{array}$ & $\begin{array}{c}2.57 \pm \\
0.01\end{array}$ & $7.3 \pm 0.3$ & $\begin{array}{c}0.2 \\
9\end{array}$ & $\begin{array}{c}0.1 \\
9\end{array}$ & $\begin{array}{c}0.0 \\
5\end{array}$ & 2.93 \\
\hline$M g{ }^{2+}$ DREAMWT & 4.95 & $\begin{array}{c}0.13 \pm \\
0.01\end{array}$ & $\begin{array}{l}1.22 \pm \\
0.08\end{array}$ & $\begin{array}{c}10.1 \pm \\
0.3\end{array}$ & $\begin{array}{c}1.8 \\
5\end{array}$ & $\begin{array}{c}0.1 \\
5\end{array}$ & $\begin{array}{c}0.0 \\
4\end{array}$ & 3.105 \\
\hline Apo DREAMNCS 1 & 4.42 & $\begin{array}{c}0.42 \pm \\
0.05\end{array}$ & $\begin{array}{l}2.15 \pm \\
0.2\end{array}$ & $\begin{array}{c}6.36 \pm \\
0.3\end{array}$ & $\begin{array}{c}0.2 \\
9\end{array}$ & $\begin{array}{c}0.1 \\
4\end{array}$ & $\begin{array}{c}0.0 \\
9\end{array}$ & 0.91 \\
\hline $\mathrm{Ca}^{2+}$ DREAMNCS 1 & 4.81 & $\begin{array}{c}0.58 \pm \\
0.03\end{array}$ & $\begin{array}{c}2.78 \pm \\
0.2\end{array}$ & $\begin{array}{c}8.11 \pm \\
0.7\end{array}$ & $\begin{array}{c}0.2 \\
7 \\
\end{array}$ & $\begin{array}{c}0.1 \\
6 \\
\end{array}$ & $\begin{array}{c}0.0 \\
5 \\
\end{array}$ & 0.75 \\
\hline $\mathrm{Mg}^{2+} \mathrm{DREAMNCS} 1$ & 3.87 & $\begin{array}{c}0.48 \pm 0 \\
.04\end{array}$ & $\begin{array}{c}2.14 \pm \\
0.3\end{array}$ & $\begin{array}{c}5.87 \pm \\
0.3\end{array}$ & $\begin{array}{c}0.3 \\
4 \\
\end{array}$ & $\begin{array}{c}0.1 \\
4 \\
\end{array}$ & $\begin{array}{c}0.0 \\
9\end{array}$ & 0.98 \\
\hline
\end{tabular}


DREAM-NCS-1 and DREAM-WT in the presence and absence of divalent metal.

To provide additional information about the changes in the hydrophobic cavities on the protein surface, I have determined the lifetime of 1,8-ANS bound to DREAM-NCS 1 in the presence and the absence of $\mathrm{Ca}^{2+}$ using frequency domain approach. The data were

Table 4.3: Decay parameters for 1,8 ANS -DREAM WT and 1,8 ANS- DREAM-NCS 1 complex in the presence and absence of $\mathrm{Ca}^{2+}$. The data were analyzed using a three exponential decay model. The data for DREAM WT are from Ref. Gonzalez and Miksovska, 2014.

\begin{tabular}{|l|l|l|l|l|l|}
\hline & $\tau_{1}(\mathrm{~ns})$ & $\tau_{2}(\mathrm{~ns})$ & $\alpha_{1}$ & $\alpha_{2}$ & $\chi^{2}$ \\
\hline 1,8 ANS Apo DREAM WT & $5.9 \pm 0.1$ & $16.2 \pm 0.7$ & 0.13 & 0.23 & 1.16 \\
\hline $1,8 \mathrm{ANS} \mathrm{Ca}^{2+}$ DREAM WT & $5.9 \pm 0.2$ & $17.6 \pm 0.5$ & 0.18 & 0.42 & 1.13 \\
\hline 1,8 ANS Apo DREAM-NCS1 & $4.72 \pm 0.2$ & $16.5 \pm 0.3$ & 0.05 & 0.04 & 2.31 \\
\hline $1,8 \mathrm{ANS} \mathrm{Ca}^{2+}$ DREAM-NCS 1 & $4.40 \pm 0.2$ & $16.4 \pm 0.3$ & 0.04 & 0.04 & 1.98 \\
\hline
\end{tabular}

analyzed using a sum of three discreet exponential decays and the decay parameters are provided in Table 4.3.. The lifetime of 1,8-ANS unbound to protein was fixed to 0.27 (Gonzalez \& Miksovska, 2014). The decay parameters for 1,8 ANS- DREAM WT were previously determined (Gonzalez \& Miksovska, 2014) and are listed for the comparison. Interestingly, the lifetimes $\tau_{1}$ and $\tau_{2}$ are similar for both the WT and the mutant, suggesting that the binding sites for 1,8-ANS are identical in DREAM WT and DREAMNCS-1. 
Site 1 and site 2 interactions with DREAM-NCS 1

Previous data shown that binding of peptides mimicking the DREAM binding site 1 and site 2 in the T1 domain of $\mathrm{K}_{\mathrm{v}}$ channel DREAM is regulated by $\mathrm{Ca}^{2+}$ and the affinity of DREAM for site 1 and site 2 increases approximately 25 and 50 times, respectively (Gonzalez and Miksovska, 2014).

Site 1 and site 2 interactions with DREAM-NCS were monitored by measuring the change in anisotropy upon DREAM-NCS 1 addition to peptides with a FITC fluorescent probe covalently attached to the $\mathrm{N}$ - terminus in the presence and absence of $\mathrm{Ca}^{2+}$. Increase in the

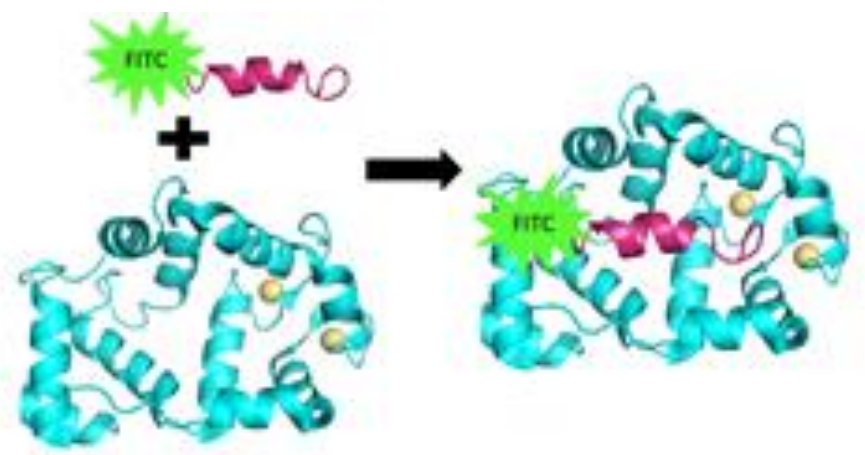

Fig. 4.9: Cartoon presentation of the interactions between FITC labeled site 1 (shown in purple) and DREAM (shown in light blue). $\mathrm{Ca}^{2+}$ ions are shown in yellow.

size of the FITC-labeled peptide upon complexation with DREAM protein (see Scheme 4.1) results in the increase in the anisotropy. Thus monitoring an increase in anisotropy as a function of the increased concentration of DREAM provides a convenient way determine the affinity of DREAM for individual peptides.

The titration curves for site 2 and site 1 binding to DREAM-NCS- 1 in the absence and presence of $\mathrm{Ca}^{2+}$ are shown in Fig. 4.10 and Fig. 4.11, respectively. For both sites, the 
anisotropy increases upon protein addition, suggesting that the chimeric protein binds both peptide. Analysis of titration curves using a quadratic equation as described in Material and Method section, provided equilibrium dissociation constants that are listed in Table 4.4.
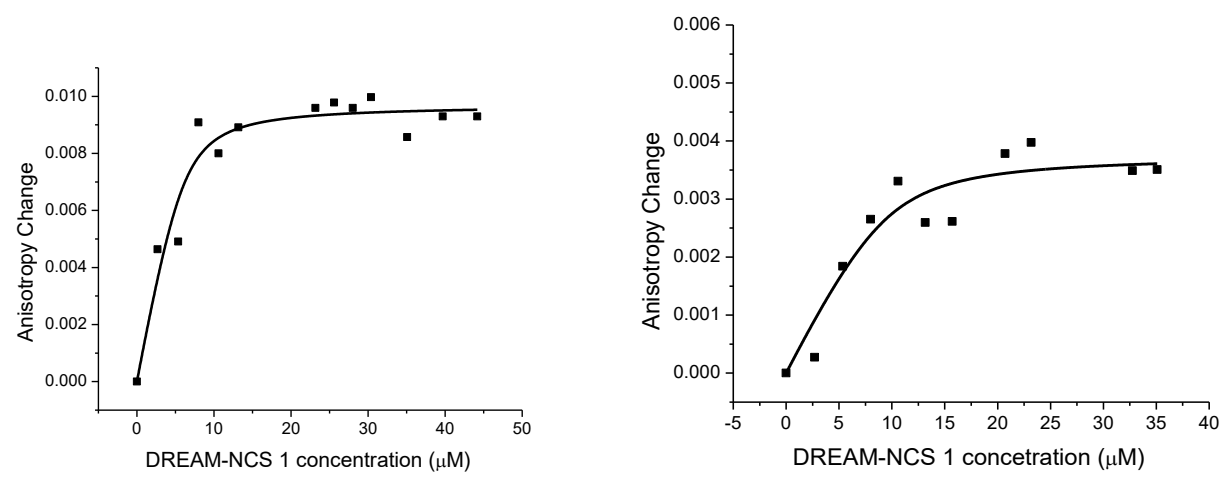

Fig. 4.10: Increase in anisotropy for Site 2 titration with DREAM -NCS 1 in the presence (left) and absence (right) of $\mathrm{Ca}^{2+}$. The solid line corresponds to the fit of the experimental data using quadratic equation (Eq. 2.5)
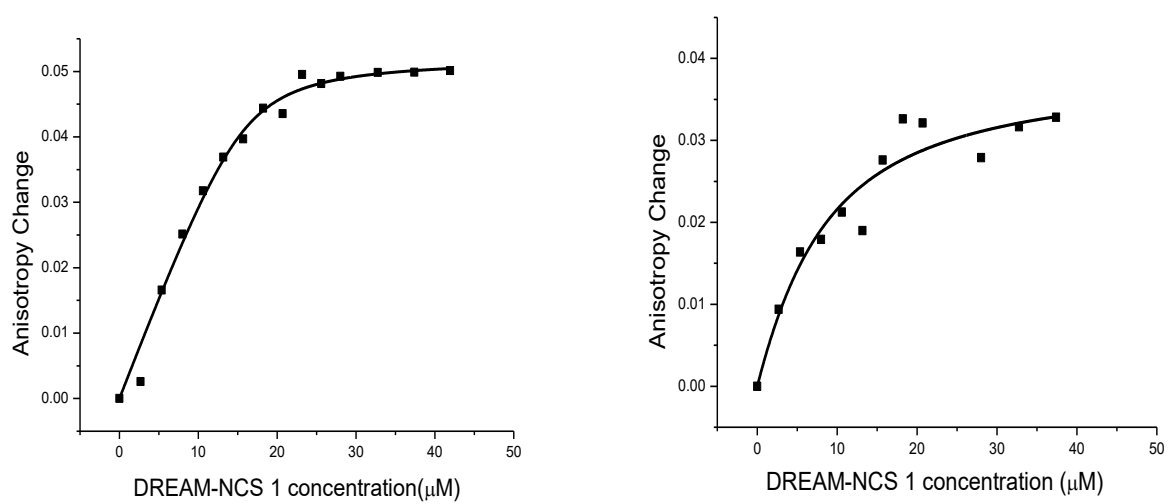

Fig. 4.11: Increase in anisotropy for Site 1 titration with DREAM -NCS 1 in the presence (left) and absence (right) of $\mathrm{Ca}^{2+}$. The solid line corresponds to the fit of the experimental data using quadratic equation (Eq. 2.5) 
Table 4.4: Dissociation constant for DREAM-NCS 1 interactions with Site 1 and Site 2 peptides, in the presence and absence of $\mathrm{Ca}^{2+}$.

\begin{tabular}{|c|c|}
\hline & $\mathrm{K}_{\mathrm{D}}(\mu \mathrm{M})$ \\
\hline Apo DREAM-NCS 1- Site 1 & $13.7 \pm 0.8$ \\
\hline Apo DREAM-NCS 1 - Site 2 & $3.9 \pm 0.60$ \\
\hline $\mathrm{Ca}^{2+}$ DREAM-NCS 1 Site 1 & $7.9 \pm 0.8$ \\
\hline $\mathrm{Ca}^{2+}$ DREAM-NCS 1 Site 2 & $9.0 \pm 1.9$ \\
\hline
\end{tabular}

The equilibrium dissociation constants determined for site 1 and site 2 binding to DREAMNCS-1 chimeric variant show an increased affinity compared to DREAM WT data and more importantly, the affinity for site 1 and site 2 is only weakly influenced by the presence of $\mathrm{Ca}^{2+}$ as the affinity for site 1 increases only two times in the presence of $\mathrm{Ca}^{2+}$ whereas affinity of $\mathrm{Ca}^{2+}$ bound DREAM-NCS-1 is approximately 2.5 weaker in the presence of $\mathrm{Ca}^{2+}$ compared to the metal free protein.

\subsection{Discussion}

Here we present the characterization of structural and functional properties of the chimeric DREAM-NCS-1. The Trp 169 emission spectra indicate that the replacement of Leu residues by Ser and Thr as well as modification of the loop between EF-hand 3 and EFhand 4 strongly impact the Trp 169 surrounding as the emission spectra are red shifted, likely due to the more polar environment of the intrinsic probe. The different transition 
upon $\mathrm{Ca}^{2+}$ binding to apoDREAM-NCS-1 compared to DREAM WT was observed, i.e. increase in the emission intensity, indicating distinct changes in the tertiary structure of the chimeric protein in the presence of $\mathrm{Ca}^{2+}$ Interestingly, similar increase in the emission intensity upon $\mathrm{Ca}^{2+}$ association was observed previously for $\mathrm{Ca}^{2+}$ binding to NCS-1 (Aravind et al., 2008) (Aravid et al, 2008)[JM8],suggesting that photo-physical properties of Trp 169 in the chimeric protein resemble to those observed for NCS-1, at least in the presence of $\mathrm{Ca}^{2+}$. However, the Trp 169 lifetime data determined for the chimeric DREAM-NCS-1 f or DREAM-WT suggest similar dynamic properties of Trp 169 and its surrounding in both proteins. The CD data clearly demonstrate that despite the red shift in the Trp emission spectrum, the chimeric protein has similar secondary structure DREAM WT and thus the absence of Leu 158 and Leu 159 residues as well as substitution of residues in the loop connecting EF-hand 3 and EF-hand 4 did not perturbed the proteins structure. The emission spectra of 1,8-ANS probe bound to apo DREAM-NCS-1 and $\mathrm{Ca}^{2+}$ bound DREAM-NCS-1 ( $\lambda_{\max }=471 \mathrm{~nm}$ and $491 \mathrm{~nm}$, respectively) are red shifted with respect to the maxima of 1,8-ANS bound apoDREAM WT and 1,8-ANS bound $\mathrm{Ca}^{2+}$ DREAM $\left(\lambda_{\max }=461\right.$ for both adducts, Gonzalez and Miksovska, 2014 ), suggesting that hydrophobic cavities are somewhat more polar in the chimeric protein. In addition, the affinity of the dimeric protein for 1,8-ANS increases 6 times and 3 times in the absence and presence of $\mathrm{Ca}^{2+}$, respectively. We associate the increase in the affinity for a,8-ANS with the absence of the tetrameric and dimeric state in the apo and $\mathrm{Ca}^{2+}$ bound form of DREAM-NCS-1 due to the increased accessibility of the hydrophobic cavities.

The chimeric version of the protein interacts more closely with the peptides mimicking the site 1 and site 2 binding sites in the Kv channel T1 domain. Analogously with the increased 
affinity for 1,8-ANS, these data indicates increased accessibility of the site 1 and site 2 binding sites on the protein surface due to the lack of the apoDREAM-NCS-1 tetramer and $\mathrm{Ca}^{2+}$ DREAM-NCS-1 dimer. Interestingly, $\mathrm{Ca}^{2+}$ regulated increase affinity of DREAM WT for site 1 and site 2 is not observed in this construct, suggesting, that the presence of the dimeric form is necessary for $\mathrm{Ca}^{2+}$ regulation of DREAM affinity for site 1 and site 2 binding sites.

Although these data points towards a distinct oligomerization form of chimeric DREAMNCS-1 protein, additional experiments, that directly monitor the changes in protein oligomerization, such as dynamic light scattering, are necessary to confirm the above results. Also, molecular dynamic studies will provide insight into the distinct structural properties of DREAM-NCS-1. 


\section{LIST OF REFERENCES}

Ames, J. B. (2018). Dimerization of neuronal calcium sensor proteins. Frontiers in Molecular Neuroscience, 11, 397. doi:10.3389/fnmol.2018.00397

Ames, J. B., \& Lim, S. (2012). Molecular structure and target recognition of neuronal calcium sensor proteins. BBA - General Subjects, 1820(8), 1205-1213. doi:10.1016/j.bbagen.2011.10.003

Aravind, P., Chandra, K., Reddy, P. P., Jeromin, A., Chary, K. V. R., \& Sharma, Y. (2008). Regulatory and structural EF-hand motifs of neuronal calcium sensor-1: $\mathrm{Mg} 2+$ modulates $\mathrm{Ca} 2+$ binding, $\mathrm{Ca} 2+$-induced conformational changes, and equilibrium unfolding transitions. Journal of Molecular Biology, 376(4), 1100-1115. doi:10.1016/j.jmb.2007.12.033

Azam, S., \& Miksovska, J. (2019). Pb2+ binds to downstream regulatory element antagonist modulator (DREAM) and modulates its interactions with binding partners: A link between neuronal calcium sensors and $\mathrm{Pb} 2+$ neurotoxicity. ACS Chemical Neuroscience, 10(3), 1263-1272. doi:10.1021/acschemneuro.8b00335

Bähring, R. (2018). Kv channel-interacting proteins as neuronal and non-neuronal calcium sensors. Channels, 12(1), 187-200. doi:10.1080/19336950.2018.1491243

Braunewell, K. H., Spilker, C., Behnisch, T., \& Gundelfinger, E. D. (1997). The neuronal calcium-sensor protein VILIP modulates cyclic AMP accumulation in stably transfected C6 glioma cells: Amino-terminal myristoylation determines functional activity. Journal of Neurochemistry, 68(5), 2129-2139. doi:10.1046/j.14714159.1997.68052129.x

Braunewell, K., \& Gundelfinger, E. D. (1999). Intracellular neuronal calcium sensor proteins: A family of EF-hand calcium-binding proteins in search of a function. Cell \& Tissue Research, 295(1), 1-12. doi:10.1007/s004410051207

Burgoyne, R. D., \& Weiss, J. L. (2001). The neuronal calcium sensor family of Ca2+binding proteins (vol 353,pg 1, 2001). Biochemical Journal, 354, 727. doi:10.1042/0264-6021:3540727v

Burgoyne, R. D., \& Haynes, L. P. (2012). Understanding the physiological roles of the neuronal calcium sensor proteins. Molecular Brain, 5(1), 2. doi:10.1186/1756-6606$5-2$ 
Calvert, P. D., Klenchin, V. A., \& Bownds, M. D. (1995). Rhodopsin kinase inhibition by recoverin. function of recoverin myristoylation. The Journal of Biological Chemistry, 270(41), 24127-24129. doi:10.1074/jbc.270.41.24127

Carrión, A. M., Link, W. A., Ledo, F., Mellström, B., \& Naranjo, J. R. (1999). DREAM is a Ca2+-regulated transcriptional repressor. Nature, 398(6722), 80-84. doi:10.1038/18044

Chazin, W. J. (2011). Relating form and function of EF-hand calcium binding proteins. Accounts of Chemical Research, 44(3), 171-179. doi:10.1021/ar100110d

Cheng, H. M., \& Penninger, J. M. (2004). DREAMing about arthritic pain. Annals of the Rheumatic Diseases, 63(suppl 2), ii72-ii75. doi:10.1136/ard.2004.029942

Dason, J., Romero-Pozuelo, J., Atwood, H., \& Ferrús, A. (2012). Multiple roles for frequenin/NCS-1 in synaptic function and development. Molecular Neurobiology, 45(2), 388-402. doi:10.1007/s12035-012-8250-4

Dong, Z., Saikumar, P., Weinberg, J. M., \& Venkatachalam, M. A. (2006). Calcium in cell injury and death. Annual Review of Pathology-Mechanisms of Disease, 1(1), 405-434. doi:10.1146/annurev.pathol.1.110304.100218

Findeisen, F., Hura, G. L., Minor, D. L., \& Pioletti, M. (2006). Three-dimensional structure of the KChIP1-Kv4.3 T1 complex reveals a cross-shaped octamer. Nature Structural \& Molecular Biology, 13(11), 987-995. doi:10.1038/nsmb1164

Gasymov, O. K., \& Glasgow, B. J. (2007). ANS fluorescence: Potential to augment the identification of the external binding sites of proteins. BBA - Proteins and Proteomics, 1774(3), 403-411. doi:10.1016/j.bbapap.2007.01.002

Gifford, J. L., Walsh, M. P., \& Vogel, H. J. (2007). Structures and metal-ion-binding properties of the Ca2+-binding helix-loop-helix EF-hand motifs. The Biochemical Journal, 405(2), 199-221. doi:10.1042/BJ20070255

Gonzalez, W. G., \& Miksovska, J. (2014). Application of ANS fluorescent probes to identify hydrophobic sites on the surface of DREAM. BBA - Proteins and Proteomics, 1844(9), 1472-1480. doi:10.1016/j.bbapap.2014.05.004

Greenfield, N. J. (2007). Using circular dichroism spectra to estimate protein secondary structure. Nature Protocols, 1(6), 2876-2890. doi:10.1038/nprot.2006.202

Jameson, D. M. (2014). Introduction to fluorescence. Boca Raton, FL: CRC Press. doi:10.1201/b16502 
Lakowicz, J. R. (2006). Principles of fluorescence spectroscopy. Boston: Springer. doi:10.1007/978-0-387-46312-4

Li, C., Pan, W., Braunewell, K. H., \& Ames, J. B. (2011). Structural analysis of $\mathrm{Mg} 2+$ and $\mathrm{Ca} 2+\mathrm{Binding}$, myristoylation, and dimerization of the neuronal calcium sensor and visinin-like protein 1 (VILIP-1). The Journal of Biological Chemistry, 286(8), 6354-6366. doi:10.1074/jbc.M110.173724

Lilliehook, C., Buxbaum, J. D., Wasco, W., Merriam, D. E., Luo, Y., Crowley, A. C., \& Choi, E. (1998). Calsenilin: A calcium-binding protein that interacts with the presenilins and regulates the levels of a presenilin fragment. Nature Medicine, 4(10), 1177-1181. doi:10.1038/2673

Ling, H., Hinson, J. W., Cao, J., Betty, M., Mattsson, K. I., An, W. F., . . Bowlby, M. R. (2000). Modulation of A-type potassium channels by a family of calcium sensors. Nature, 403(6769), 553-556. doi:10.1038/35000592

Lock, J. T., Smith, I. F., \& Parker, I. (2019). Spatial-temporal patterning of Ca2+ signals by the subcellular distribution of IP3 and IP3 receptors. Seminars in Cell and Developmental Biology, 94, 3-10. doi:10.1016/j.semcdb.2019.01.012

López-Hurtado, A., Burgos, D. F., González, P., Dopazo, X. M., González, V., Rábano, A., . . Naranjo, J. R. (2018). Inhibition of DREAM-ATF6 interaction delays onset of cognition deficit in a mouse model of huntington's disease. Molecular Brain, 11(1), 1-8. doi:10.1186/s13041-018-0359-6

Lusin, J. D., Vanarotti, M., Li, C., Valiveti, A., \& Ames, J. B. (2008). NMR structure of DREAM: Implications for $\mathrm{Ca} 2+-$ dependent DNA binding and protein dimerization. Biochemistry, 47(8), 2252-2264. doi:10.1021/bi7017267

Maret, W., \& Li, Y. (2009). Coordination dynamics of zinc in proteins. Chemical Reviews, 109(10), 4682-4707. doi:10.1021/cr800556u

Martinez, J. C., Murciano-Calles, J., Cobos, E. S., Iglesias-Bexiga, M., Luque, I., \& RuizSanz, J. (Eds.). (2013). Isothermal titration calorimetry: Thermodynamic analysis of the binding thermograms of molecular recognition events by using equilibrium models. InTech. doi:10.5772/53311

Masanori Osawa, Alexandra Dace, Kit I. Tong, Aswani Valiveti, Mitsuhiko Ikura, \& James B. Ames. (2005). $\mathrm{Mg} 2+$ and $\mathrm{Ca} 2+$ differentially regulate DNA binding and dimerization of DREAM. Journal of Biological Chemistry, 280(18), 18008-18014. doi:10.1074/jbc.M500338200

Myers, W. K., Xu, X., Li, C., Lagerstedt, J. O., Budamagunta, M. S., Voss, J. C., . . Ames, J. B. (2013). Double Electron-Electron resonance probes Ca2+-induced 
conformational changes and dimerization of recoverin. Biochemistry, 52(34), 58005808. doi:10.1021/bi400538w

Ooi, L., \& Wood, I. C. (2008). Regulation of gene expression in the nervous system. The Biochemical Journal, 414(3), 327-341. doi:10.1042/BJ20080963

Pandalaneni, S., Karuppiah, V., Saleem, M., Haynes, L. P., Burgoyne, R. D., Mayans, O., ... Lian, L. (2015). Neuronal calcium sensor-1 binds the D2 dopamine receptor and G-protein-coupled receptor kinase 1 (GRK1) peptides using different modes of interactions. The Journal of Biological Chemistry, 290(30), 18744-18756. doi:10.1074/jbc.M114.627059

Permyakov, E. A., \& Kretsinger, R. H. (2011). Calcium binding proteins (1st ed.). Hoboken, NJ: John Wiley \& Sons.

Permyakov, S. E., Cherskaya, A. M., Wasserman, L. A., Khokhlova, T. I., Senin, I. I., Zargarov, A. A., . . Permyakov, E. A. (2003). Recoverin is a zinc-binding protein. Journal of Proteome Research, 2(1), 51-57. doi:10.1021/pr025553i

Ping Liang, Huayi Wang, Hao Chen, Yuanyuan Cui, Lichuan Gu, Jijie Chai, \& KeWei Wang. (2009). Structural insights into KChIP4a modulation of Kv4.3 inactivation. Journal of Biological Chemistry, 284(8), 4960-4967. doi:10.1074/jbc.M807704200

Plum, L. M., Rink, L., \& Haase, H. (2010). The essential toxin: Impact of zinc on human health. International Journal of Environmental Research and Public Health, 7(4), 1342-1365. doi:10.3390/ijerph7041342

Pongs, O., Lindemeier, J., Zhu, X. R., Theil, T., Engelkamp, D., Krah-Jentgens, I., . . . Ferrús, A. (1993). Frequenin - A novel calcium-binding protein that modulates synaptic efficacy in the drosophila nervous system. Neuron, 11(1), 15-28. doi:10.1016/0896-6273(93)90267-U

Ramirez, D., Gonzalez, W., Fissore, R. A., \& Carvacho, I. (2017). Conotoxins as tools to understand the physiological function of voltage-gated calcium (ca-V) channels. Marine Drugs, 15(10), 313. doi:10.3390/md15100313

Smith, T. F., \& Waterman, M. S. (1981). Identification of common molecular subsequences. Journal of Molecular Biology, 147(1), 195-197. doi:10.1016/00222836(81)90087-5

Stryer, L. (1965). The interaction of a naphthalene dye with apomyoglobin and apohemoglobin. A fluorescent probe of non-polar binding sites. Journal of Molecular Biology, 13(2), 482. doi:10.1016/S0022-2836(65)80111-5 
Vallee, B. L., \& Falchuk, K. H. (1993). The biochemical basis of zinc physiology. Physiological Reviews, 73(1), 79-118. doi:10.1152/physrev.1993.73.1.79

Warren, J. T., Guo, Q., \& Tang, W. (2007). A 1.3 domain of calmodulin elucidates potential early ion-binding step. Journal of Molecular Biology, 374(2), 517-527. doi:10.1016/j.jmb.2007.09.048

Wei, Y., Thyparambil, A. A., \& Latour, R. A. (2014). Protein helical structure determination using $\mathrm{CD}$ spectroscopy for solutions with strong background absorbance from 190-230 nm. Biochimica Et Biophysica Acta, 1844(12), 2331-2337. doi:10.1016/j.bbapap.2014.10.001

Yu, L., Sun, C., Mendoza, R., Wang, J., Matayoshi, E. D., Hebert, E., . . Olejniczak, E. T. (2007). Solution structure and calcium-binding properties of EF-hands 3 and 4 of calsenilin. Protein Science, 16(11), 2502-2509. doi:10.1110/ps.072928007 